\title{
A Study of the Interaction between Typhoon Francisco (2013) and a Cold-Core Eddy. Part I: Rapid Weakening
}

\author{
ZHANHONG MA \\ College of Meteorology and Oceanography, National University of Defense Technology, Nanjing, China
}

(Manuscript received 27 December 2018, in final form 19 August 2019)

\begin{abstract}
Typhoon Francisco (2013) experienced unusually rapid weakening (RW) with its maximum surface wind decreasing by $45 \mathrm{kt}\left(1 \mathrm{kt} \approx 0.51 \mathrm{~m} \mathrm{~s}^{-1}\right)$ over $24 \mathrm{~h}$ as measured from the satellite-derived advanced Dvorak technique (ADT) dataset, which is more than twice the weakening rate defined as RW by DeMaria. The mechanisms leading to the extreme RW event of Francisco are examined based on observational analysis and simulations by coupling the Weather Research and Forecasting (WRF) Model, version 3.7, with the Stony Brook Parallel Ocean Model (sbPOM). The RW of Francisco took place in a relatively favorable atmospheric environment while passing over detrimental oceanic conditions, dominated by the presence of a cold-core eddy. The passages of two prior typhoons apparently intensified the cold-core eddy, contributing to a major role of eddy feedback on RW for Francisco. The structural changes in Francisco accompanying eddy interaction are characterized by a substantially enlarged eye size, which evolved from $\sim 20$ to $\sim 100 \mathrm{~km}$ in diameter, as indicated from satellite images. Numerical simulations suggest that the eddy is prominent in weakening the intensity of Francisco during the storm-eddy interaction, with its role less significant but still comparable to that of the cold wake. Both the cooler water and stronger upward motion in the eddy lead to a larger sea surface temperature decrease induced by Francisco, which results in a nearly $50 \%$ decrease of surface enthalpy flux, suppressed convective bursts, and a 50\% reduction in latent heat release. These results underscore the potential importance of open-ocean, cold-core eddies in contributing to the RW of tropical cyclones.
\end{abstract}

\section{Introduction}

The progress in tropical cyclone (TC) intensity forecast improvement has been slow in recent decades relative to the rate of improvement in TC track prediction, since the intensity change is influenced by multiscale processes, such as large-scale environmental factors, vortex dynamics, and air-sea interactions (Emanuel et al. 2004; Black et al. 2007; Elsberry et al. 2007; Rogers et al. 2013; DeMaria et al. 2014; Colomb et al. 2019). The sudden intensity change of TCs, including both rapid intensification (RI) and rapid weakening (RW), consists of an important source of intensity forecasting errors (Elsberry et al. 2007; Kaplan et al. 2010, 2015; Rozoff and Kossin 2011; Wood and Ritchie 2015; Liang et al. 2016, 2018). Nonetheless, there is occasional singleseason success in predicting RI with specific models such as the operational Hurricane Weather Research and Forecast (HWRF) Model for TCs over the western

\footnotetext{
Corresponding author: Zhanhong Ma, mazhanhong17@nudt. edu.cn
}

North Pacific in 2013 (Tallapragada and Kieu 2014). Tallapragada and Kieu (2014) also show prediction of open-ocean weakening events for the cases described in this paper (i.e., Danas and Francisco). However, delayed RW onset is predicted for Danas and the magnitude of the weakening rate is underforecast for Francisco, failing to meet the RW criteria of DeMaria et al. (2012). These errors are likely a result of lack of ocean coupling in these HWRF Model simulations, highlighting the necessity to explore underlying air-sea mechanisms leading to the sudden RW of TC intensity.

The existing literature focuses very much on the processes or structural changes responsible for the RI of TCs (e.g., Hendricks et al. 2010; Wang and Wang 2014; Chen and Gopalakrishnan 2015; Miyamoto and Nolan 2018), wherein the behaviors of convective bursts (CBs) are found to have a close link with the onset of RI (e.g., Chen and Zhang 2013; Wang and Wang 2014; Tallapragada and Kieu 2014; Chen and Gopalakrishnan 2015). Chang and Wu (2017) investigated the processes leading to the RI of a TC. They pointed out that the increased latent heat release accompanying active convections is essential for driving 
the secondary circulation and thereafter strengthening the primary circulation by inward transport of angular momentum. Although there have been increasing endeavors in understanding the RI, the work examining the RW of TCs are still rather limited. Based on statistical analysis, DeMaria et al. (2012) defined the RW as a 20-kt (roughly $10.3 \mathrm{~m} \mathrm{~s}^{-1}$ ) or greater decrease in $24 \mathrm{~h}$. This criterion is used in this study as the definition of RW. They observed that RW events occur more commonly over regions with stronger sea surface temperature (SST) gradients, which is also supported by the subsequent statistical work of Wood and Ritchie (2015). Liang et al. $(2016,2018)$ examined the influence of monsoon gyre on the occurrence of RW. They found that active outer-core convection favored by the monsoon gyre may prevent inward transport of moisture and mass, and consequently lead to the RW of TCs. The other large-scale environmental factors, such as vertical wind shear and dry air intrusion, could also cause RW of TCs (Zhang et al. 2007; Wood and Ritchie 2015; Colomb et al. 2019).

The air-sea interaction is one of the most crucial mechanisms controlling TC intensity (Emanuel 1986; Emanuel et al. 2004). Intense surface winds of TCs could induce evident decrease of SST, which contributes negatively to TC intensification (e.g., Cione and Uhlhorn 2003; Wu et al. 2005; Halliwell et al. 2015; Wu et al. 2016). Nonetheless, the SST response does not fully comply with the characteristics of TCs because of the nonhomogeneous oceanic environment (Lloyd and Vecchi 2011; Mei and Pasquero 2013). The mesoscale oceanic eddies, classified as cold-core eddy and warm-core eddy, are ubiquitous features in the ocean (Wang et al. 2003; Chelton et al. 2007). Warm-core eddies tend to restrain SST decrease caused by TCs while cold-core eddies are prone to promote the SST response (Lin et al. 2005, 2008, 2011; Wu et al. 2007; Jaimes and Shay 2009, 2015; Ma et al. 2013). As such, an increase in intensity, sometimes RI, may occur when TCs encounter warm-core eddies (e.g., Hong et al. 2000; Shay et al. 2000; Lin et al. 2005; McTaggart-Cowan et al. 2007). Based on idealized simulations, Ma et al. (2013) show that the intensification of TC can be inhibited by a cold-core eddy; the eddy impact tends to be more pronounced when the storm center crosses over the eddy. Ma et al. (2017) found that over $90 \%$ of TCs in the western North Pacific have encountered mesoscale oceanic eddies during their lifetimes; cold-core eddies are statistically more significant than warm-core eddies in modulating the SST response. Although TCs interact with cold-core eddies at very high frequencies, not all eddies have significant impact on the intensity change of TCs (Fig. 4a in Ma et al. 2018), implying that more attention should possibly be paid to the cold-core eddies with great strength or in the subtropical region where the background warm layer is shallow (Lin et al. 2008; Ma et al. 2018).

Walker et al. (2014) recorded an unpredicted rapid weakening of Hurricane Kenneth (2005) when it stalled over a cold-core eddy, which caused a decrease of sea surface cooling as large as $8^{\circ}-9^{\circ} \mathrm{C}$. Their observation implies that other than large-scale atmospheric factors, the interaction with cold-core eddies could be one reason for the RW of TCs. However, it remains unclear how the cold-core eddy contributes to the RW of TCs, as well as the changes in structures and internal processes during the RW stage. With such a focus, a case study of typhoon-eddy interaction is conducted based on both observations and numerical simulations. An atmosphereocean coupling model system with the Weather Research and Forecasting (WRF) Model, version 3.7 (Skamarock et al. 2008), as the atmospheric component and the Stony Brook Parallel Ocean Model (sbPOM; Jordi and Wang 2012) as the oceanic component is used to model typhoonocean interactions. Section 2 introduces the typhoon case together with its background and observational evidence. The model configurations, verification of simulations, and detailed analysis are presented in section 3, followed by conclusions in section 4 .

\section{Observations}

\section{a. Synopsis of Typhoon Francisco (2013)}

This study focuses on the weakening stage of Typhoon Francisco (2013). Francisco was a super typhoon in 2013 over the western North Pacific (Fig. 1), forming on 16 October at low latitude of about $13^{\circ} \mathrm{N}$. After its generation, it first translated equatorward and then turned poleward, with a relatively long time lingering over the warm ocean at low latitudes. During this time, it continued intensifying until about 1200 UTC 19 October 2013 based on the satellite-derived advanced Dvorak technique (ADT) dataset (Fig. 2), when it reached its peak intensity of $134.8 \mathrm{kt}\left(1 \mathrm{kt} \approx 0.51 \mathrm{~m} \mathrm{~s}^{-1}\right)$. Then Francisco experienced extreme weakening until about 1800 UTC 21 October 2013, possessing an intensity of $67.4 \mathrm{kt}$. In 24 -h time period from 1800 UTC 20 October to 1800 UTC 21 October, the maximum surface wind was dropped by $45 \mathrm{kt}$. The satellite consensus (SATCON) dataset [courtesy Cooperative Institute for Meteorological Satellite Studies (CIMSS): http://tropic.ssec.wisc.edu/real-time/ satcon/archive/2013/201326W.html] gives a wind drop of about $50 \mathrm{kt}$ during this time period (not shown). This weakening rate is twice larger than that defined as RW by DeMaria et al. (2012). Since a $40-\mathrm{kt}$ decrease in $24 \mathrm{~h}$ is in the upper $0.5 \%$ of cases over the North Atlantic and 


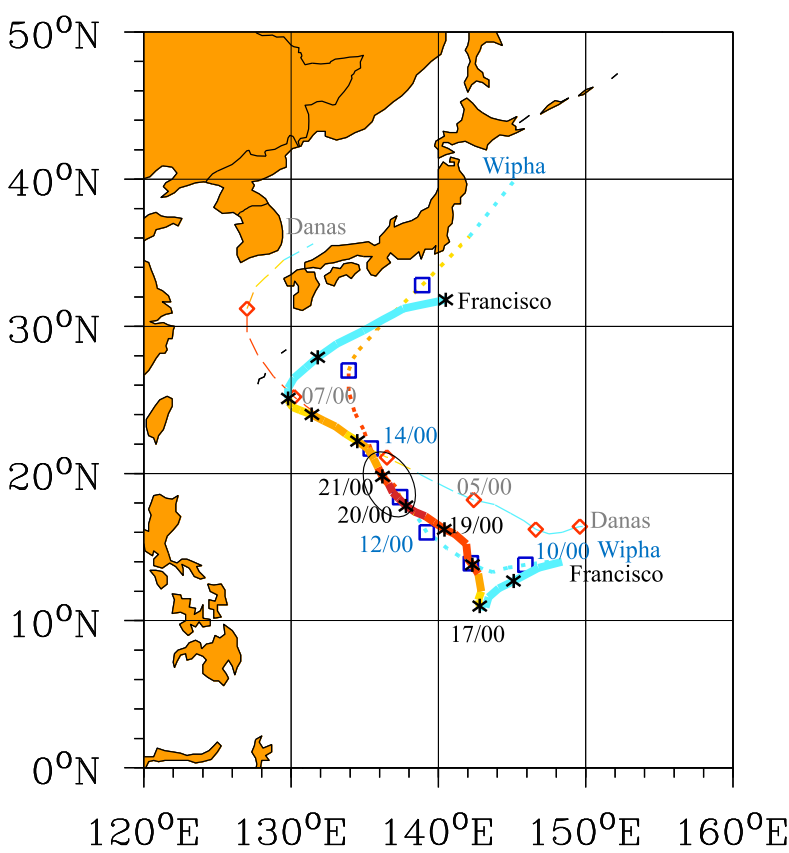

FIG. 1. A spatial map of observed tracks of Typhoons Danas (1323), Wipha (1325), and Francisco (1326) from the JTWC best track data. The tracks are marked at an interval of $24 \mathrm{~h}$ by diamonds, squares, and asterisks and are labeled by gray, blue, and black text for Danas, Wipha, and Francisco, respectively. The coldcore eddy interacting with three typhoons is marked with an ellipse. The eddy center is at $19.375^{\circ} \mathrm{N}, 136.375^{\circ} \mathrm{E}$ on 19 Oct based on Fig. 3e.

$3.5 \%$ of cases over the eastern North Pacific [indicated from Fig. 1 in Wood and Ritchie (2015)], the RW of Francisco could be close to the largest TC weakening rate on record.

\section{b. The interaction with cold-core eddy}

The RW of Francisco occurred during its passage over a cold-core eddy located at $19.375^{\circ} \mathrm{N}, 136.375^{\circ} \mathrm{E}$ on 19 October (Fig. 1), which could be a potential contributor to the extreme weakening event. Of particular interest is that there are other two typhoons crossing over the region of this eddy 1-2 weeks before and both of them experienced similar RW: one is Typhoon Danas, which underwent a wind decrease of $35 \mathrm{kt}$ from 0000 UTC 7 October to 0000 UTC 8 October (not shown); the other one is Typhoon Wipha, which had similar track as Francisco south of $21^{\circ} \mathrm{N}$ and underwent a wind decrease of $50 \mathrm{kt}$ from 0000 UTC 14 October to 0000 UTC 15 October as indicated from the ADT dataset (Fig. 2a). During the RW of Wipha, the vertical wind shear increased significantly, and may contribute considerably to its rapid intensity change (Figs. 2c,e). However, the vertical wind shear of Francisco was relatively weak and decreased during its RW stage (Figs. 2d,f), indicating that the vertical wind shear cannot be the reason for the RW of Francisco.

Danas kept intensifying when crossing over the eddy region, when the eddy cannot be detected yet (Figs. 1 and 3a). After the passage of Danas, the cold-core eddy was strengthened (Figs. 3b,c). It continued to increase in size and magnitude after the passage of the subsequent two typhoons, Wipha and Francisco (Figs. 3d-f). The eddy strength, indicated by the value of minimum sea surface height anomaly (SSHA), is about $0.08 \mathrm{~m}$ after the passage of Danas (Fig. 3b), and increases to $0.20 \mathrm{~m}$ after the passage of Wipha (Fig. 3d). Before the arrival of Francisco, the eddy strength increased to $0.24 \mathrm{~m}$ and the eddy size was amplified possibly as a result of oceanic inertial adjustment. On 19 October, the eddy size is about $4^{\circ}-5^{\circ}$ in diameter (Fig. 3e). The typhoon-induced generation or intensification of cold-core eddy in the wake of typhoons is consistent with previous observations (e.g., Sun et al. 2014). The location of cold-core eddy is basically invariant during the passage of three typhoons indicated from the minimum SSHA location (Fig. 3). This also demonstrates the resilience of the cold-core eddy to maintain its general structure after interactions with three typhoons.

Generally, the sea surface cooling induced by TCs reaches a peak value shortly after storm passages, and then is followed by a subsequent recovery period lasting for several days (Hart et al. 2007; Price et al. 2008; Dare and McBride 2011a; Mei and Pasquero 2013). However, cold-core eddies are observed to extend the time scale of SST recovery (Ma et al. 2018), as near-inertial waves could be stalled in the upper ocean of cold-core eddies (Jaimes and Shay 2010). From Fig. 4, the cold wake of Danas is less significant than that of Wipha. After the passage of Wipha, an apparent cold wake feature was formed along its track (Fig. 4d). On 19 October, before the arrival of Francisco, the cold wake of Wipha had mostly recovered, except that there was a remaining cold feature in the region of the eddy, with its minimum SST below $26^{\circ} \mathrm{C}$ (Fig. 4e). This cooled region has influenced Francisco since its track matched that of Wipha prior to and following eddy passage (Fig. 1).

Figure 5 shows the intensity evolution of Danas, Wipha, and Francisco with respect to the closest approaching to the eddy center. Both the RW of Danas and Wipha occurred after leaving the eddy center. However, Francisco underwent RW directly when crossing over the eddy region. Then Francisco left the eddy region by moving farther poleward. In the meantime, its intensity recovered moderately, consistent with the SST distribution (Fig. 4e). This suggests that the cold-core eddy has played an important role in contributing to the RW of Francisco. Although it is difficult to identify the eddy 
(a) Wipha

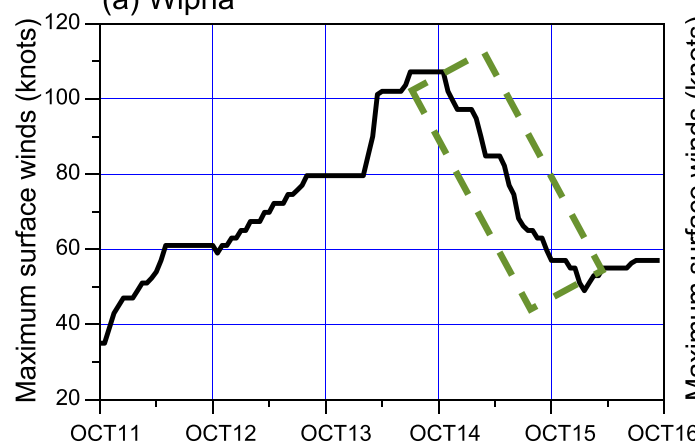

(c) Wipha

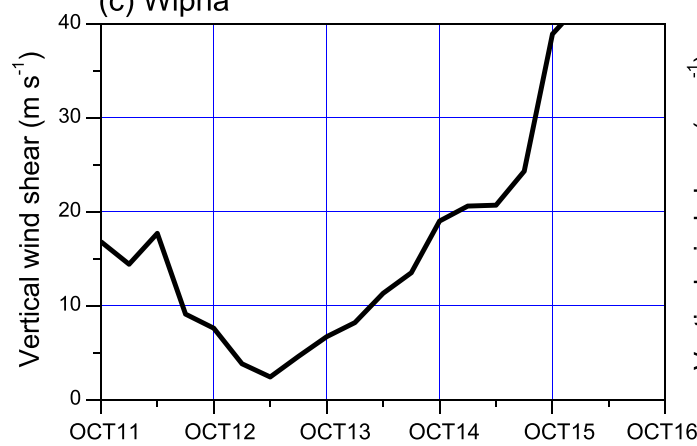

(e) Wipha

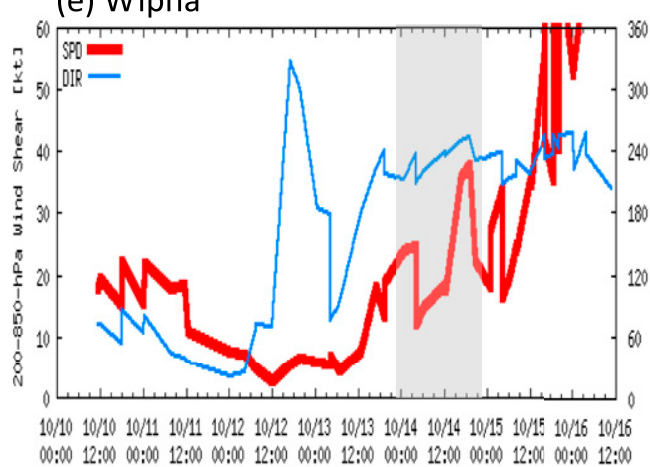

(b) Francisco

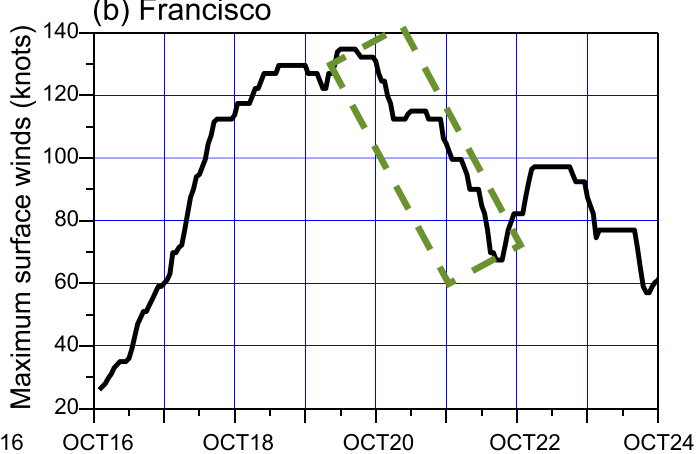

(d) Francisco

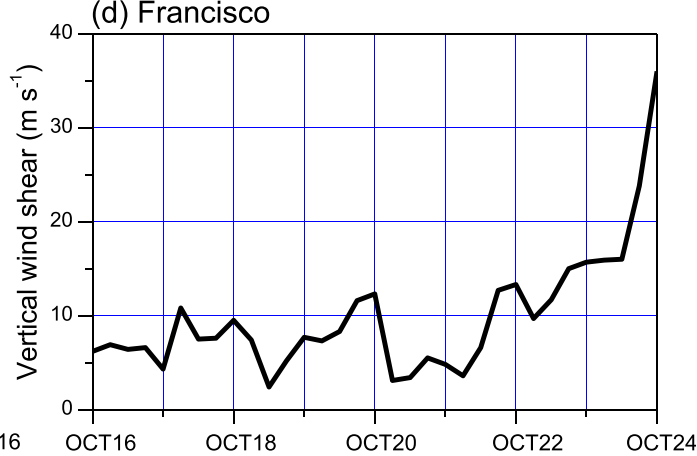

(f) Francisco

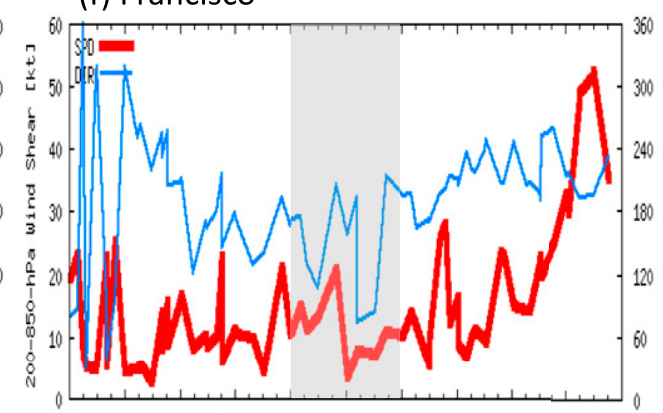

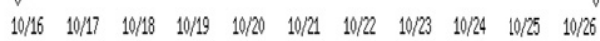

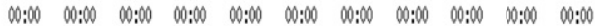

FIG. 2. Evolution of observed maximum surface wind speed (kt) for (a) Wipha and (b) Francisco from the satellite-derived advanced Dvorak technique (ADT) dataset (courtesy CIMSS: http://tropic.ssec.wisc.edu/ real-time/adt/archive2013/25W-list.txt and http://tropic.ssec.wisc.edu/real-time/adt/archive2013/26W-list.txt). The dashed boxes in (a) and (b) indicate the rapid weakening phase of each typhoon. Evolution of 850-200-hPa vertical wind shear for (c),(e) Wipha and (d),(f) Francisco. Dataset of (c) and (d) comes from the Statistical Typhoon Intensity Prediction Scheme (STIPS; courtesy RAMMB: http://rammb.cira.colostate.edu/research/ tropical_cyclones/ships/developmental_data.asp; Knaff et al. 2018). The plots in (e) and (f) are obtained from the AMSU area-averaged wind shear in RAMMB (http://rammb.cira.colostate.edu/products/tc_realtime/ storm.asp?storm_identifier=WP262013), with the red line denoting shear magnitude and shaded area denoting the RW periods of Wipha and Francisco.

role in the RW of Danas and Wipha, both of these two typhoons have increased the eddy strength and size by several times, which may be a prerequisite for the RW onset of Francisco.

The satellite imagery and simulation results are shown in Fig. 6 to demonstrate the structural changes of Francisco before and after eddy passage and RW.
Initially Francisco possessed a compact eyewall structure with a tiny eye on the order of $20 \mathrm{~km}$ in diameter (Figs. 6a,c,e). After the RW, the convection is observed to be loosely organized and the eye is broadened considerably on the order of $100 \mathrm{~km}$ in diameter (Figs. 6b,d,f). There is a tiny inner eyewall disappearing with the outer eyewall expanding due to the interaction with the 
(a) 3rd Oct Pre-Danas

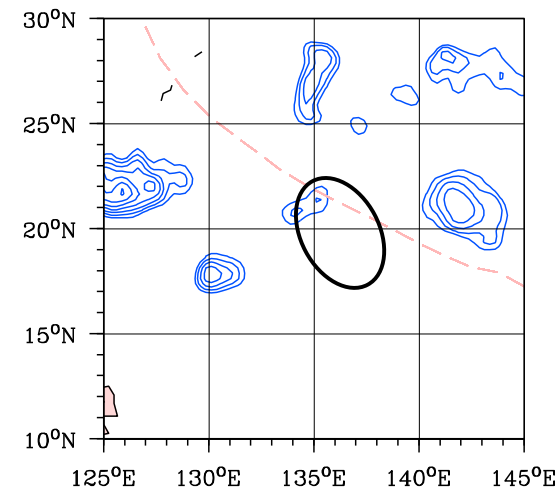

(d) 15th Oct Post-Wipha

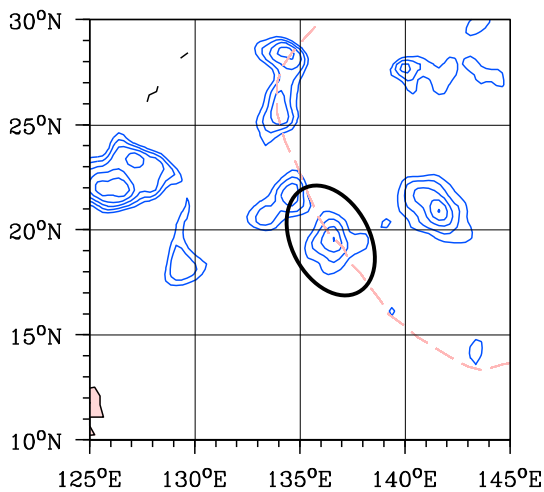

(b) 8th Oct Post-Danas

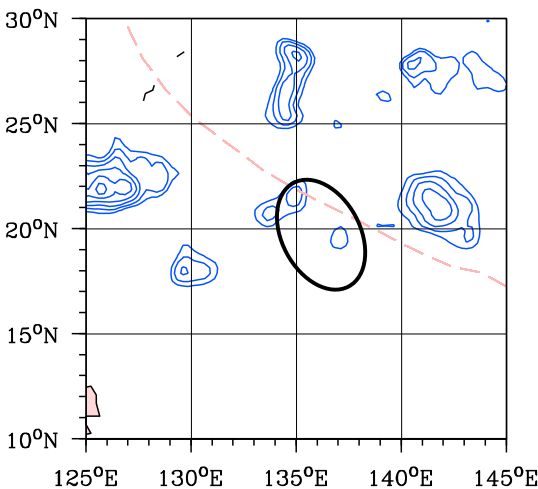

(e) 19th Oct Pre-Francisco

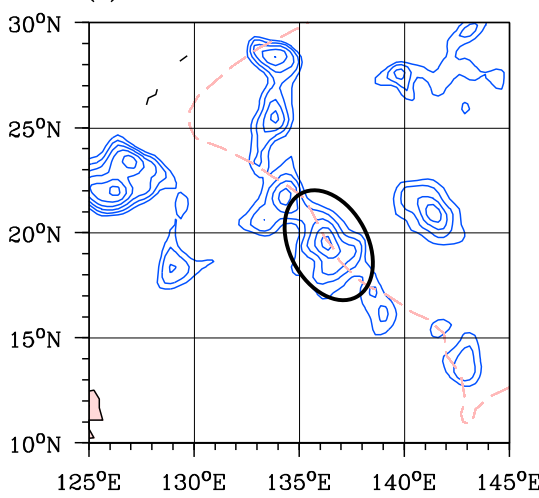

(c) 11th Oct Pre-Wipha

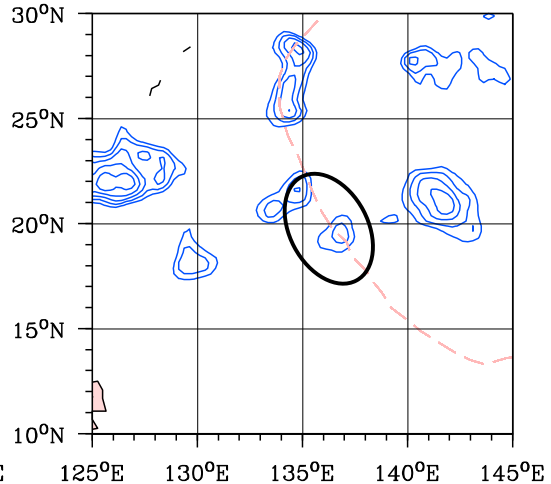

(f) 22th Oct Post-Francisco

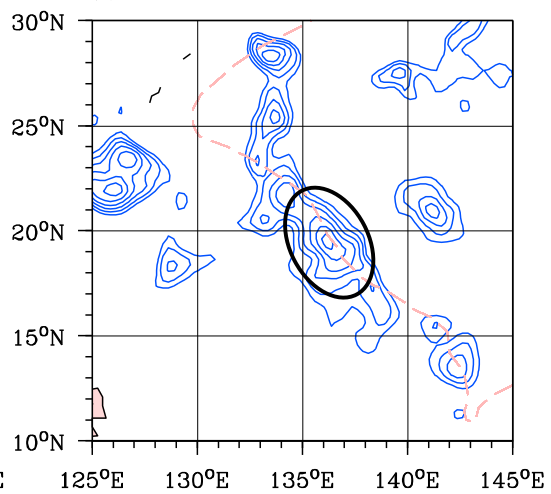

FIG. 3. Plan views of observed SSHA (m) at intervals of $0.04 \mathrm{~m}$ with the outmost contour being $0.08 \mathrm{~m}$ before and after the passage of Typhoons Danas, Wipha, and Francisco on (a) 3, (b) 8, (c) 11, (d) 15, (e) 19, and (f) 22 Oct. The observed typhoon track is superimposed with dashed line for (a),(b) Danas, (c),(d) Wipha, and (e),(f) Francisco. The cold-core eddy is marked with an ellipse, based on minimum SSHA in (e).

cold-core eddy (Figs. 6a,b). From the satellite-derived surface wind structure of the Cooperative Institute for Research in the Atmosphere (CIRA) and CIMSS product (Fig. 7), surface wind is weaker in the southwestern and southeastern quadrants indicated by the radius of 50 and $60 \mathrm{kt}$. An examination of other time series during the weakening stage gives basically consistent conclusions (not shown).

\section{Numerical simulations}

\section{a. Model configuration and experimental design}

In the atmosphere-ocean coupling model system, variables of surface wind, SST, surface enthalpy flux, and radiation flux are exchanged between the WRF Model and the sbPOM model via the Model Coupling Toolkit (MCT; Larson et al. 2005). The sbPOM model shares the same grid mesh as the outmost domain of the WRF Model for efficient computation.

In the WRF Model, the Yonsei State University (YSU) scheme (Hong et al. 2006) is adopted to parameterize the boundary layer processes. In the surface-layer scheme tied to the YSU scheme, the option "isftcflx=1" (Wang et al. 2016) is chosen so that surface drag coefficient levels off at hurricane-force $\left(33 \mathrm{~m} \mathrm{~s}^{-1}\right)$ winds (Donelan et al. 2004). The microphysical process is parameterized by the Lin scheme (Lin et al. 1983). The Rapid Radiative Transfer Model (RRTM) longwave (Mlawer et al. 1997) and Dudhia shortwave (Dudhia 1989) schemes are used as radiation schemes. The KainFritsch cumulus scheme (Kain 2004) is utilized in the outmost domain. Two domains are configured with dimensions of $350 \times 402$ and $217 \times 217$, and horizontal resolutions of 9 and $3 \mathrm{~km}$, respectively. The inner domain moves automatically with the vortex center. There are 48 uneven levels distributed as default in the vertical direction, with the vertical resolution increasing toward the surface. In the sbPOM model, a total of 40 levels are distributed as default, with 20 levels in the upper $100 \mathrm{~m}$. The centered advection and second-order pressure gradient schemes are selected.

The initialization procedure for the coupled model is as follows. The reanalysis data from National Centers for Environment Prediction (NCEP) Global Forecast 
(a) 3rd Oct Pre-Danas

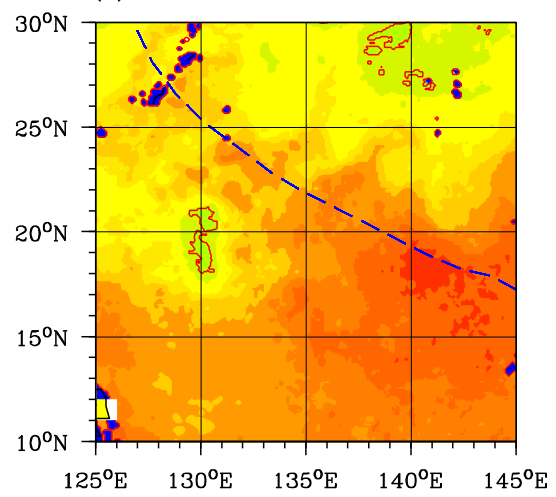

(d) 15 th Oct Post-Wipha

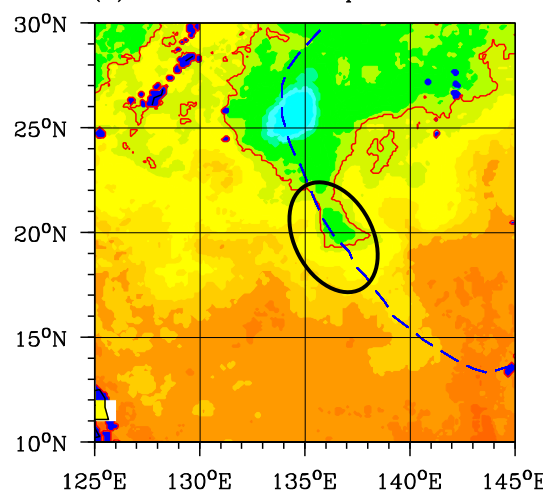

(b) 8th Oct Post-Danas

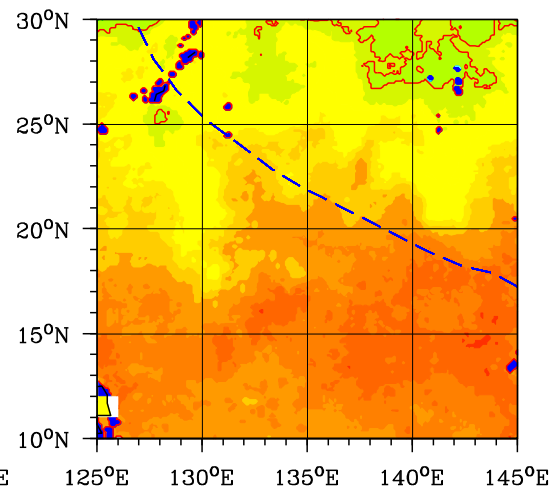

(e) 19 th Oct Pre-Francisco

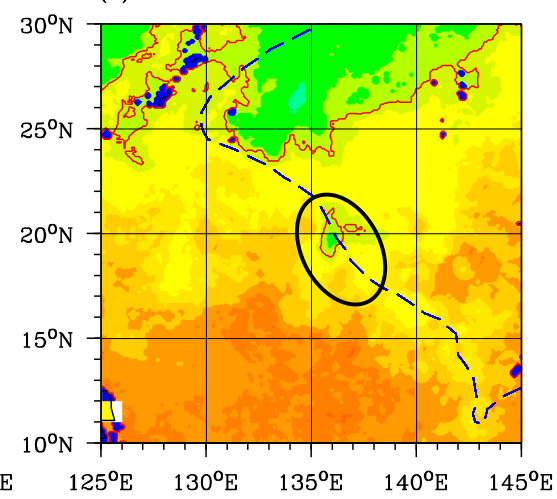

(c) 11 th Oct Pre-Wipha

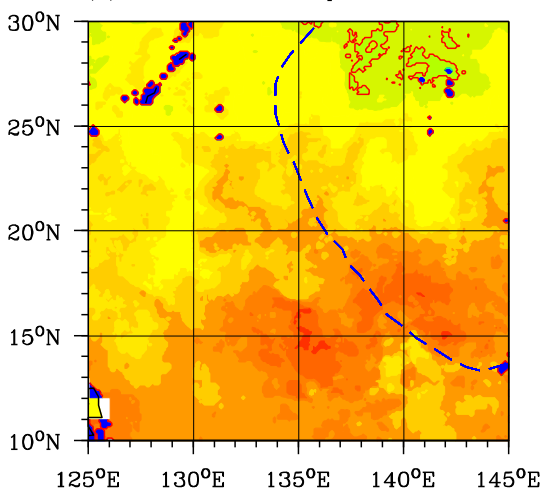

(f) 22th Oct Post-Francisco

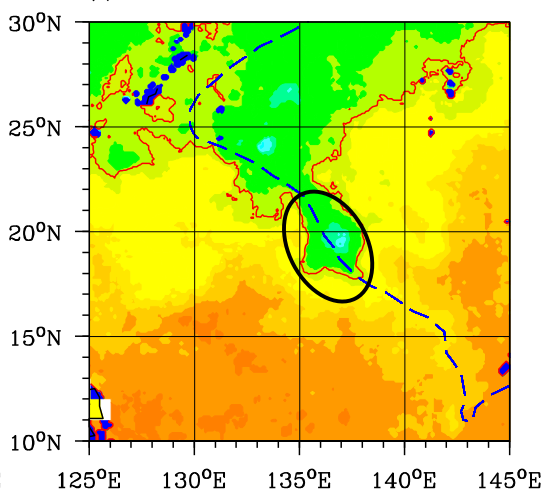

\begin{tabular}{l|l|l|l|l|l|l|l|l|l|l|l|l|l|l|l|l|l|l|l|l}
\hline & & & & & & & & & & & & & & & &
\end{tabular}

FIG. 4. As in Fig. 3, but for SST ( ${ }^{\circ} \mathrm{C}$; shaded). Red lines denote the contours of $26^{\circ} \mathrm{C}$.

System (GFS) Final Analysis (FNL) at a resolution of $1^{\circ} \times 1^{\circ}$ and at an interval of $6 \mathrm{~h}$ are used as initial fields and lateral boundaries for the WRF Model. Since the main interest of this study is the RW stage shortly after Francisco reaching its peak intensity, the formal simulation starts at 0000 UTC 19 October and ends at 0000 UTC 23 October for all experiments, with an integration of $96 \mathrm{~h}$. Because the vortex intensity from the GFS reanalysis data is too weak compared to that from the best-track observation when Francisco approximately reached its peak intensity (not shown), the WRF Model is first integrated individually for $24 \mathrm{~h}$, starting from 0000 UTC 18 October, as a spinup of the TC. At 0000 UTC 19 October, the intensity of the modeled Francisco is $932 \mathrm{hPa}$ in terms of the minimum sea level pressure and is $57.75 \mathrm{~m} \mathrm{~s}^{-1}$ in terms of the maximum $10-\mathrm{m}$ surface wind, which is close to the ADT value $\left(929 \mathrm{hPa}\right.$ and $\left.65.3 \mathrm{~m} \mathrm{~s}^{-1}\right)$. Then the output data are used as the initial fields of formal simulations.

The initial and boundary conditions of the sbPOM model come from the global reanalysis data of Hybrid Coordinate Ocean Model (HYCOM) ocean analysis/forecast system and the Navy Coupled Ocean Data Assimilation
(NCODA) components (HYCOM+NCODA) provided by the U.S. Navy Global Ocean Forecasting System (GOFS; Metzger et al. 2010). The daily HYCOM+ NCODA data have a horizontal resolution of $\sim 1 / 12^{\circ}$, making the initial field of ocean model eddy resolving. At the initial time of simulation, the cold-core eddy with lower sea level height than its surroundings is directly below the track of Francisco.

Three numerical experiments are conducted to explore the effect of cold-core eddy and cold wake. A coupled experiment with default HYCOM+NCODA data as the initial oceanic field is considered as the control run and denoted as COUP. To isolate the contribution of cold-core eddy, a second coupled experiment by removing the eddy from the initial oceanic field is conducted and denoted as NOED. The procedure for removing the eddy is as follows: based on the observed SSHA on 19 October (Fig. 3e), the eddy is centered at $19.375^{\circ} \mathrm{N}, 136.375^{\circ} \mathrm{E}$ with a diameter of $4^{\circ}-5^{\circ}$; then all the oceanic data within a radius of $2^{\circ}$ from the eddy center are removed and replaced by surrounding environmental profiles, which are calculated by averaging the oceanic data within radii of $2.5^{\circ}-3.0^{\circ}$ relative to the eddy 


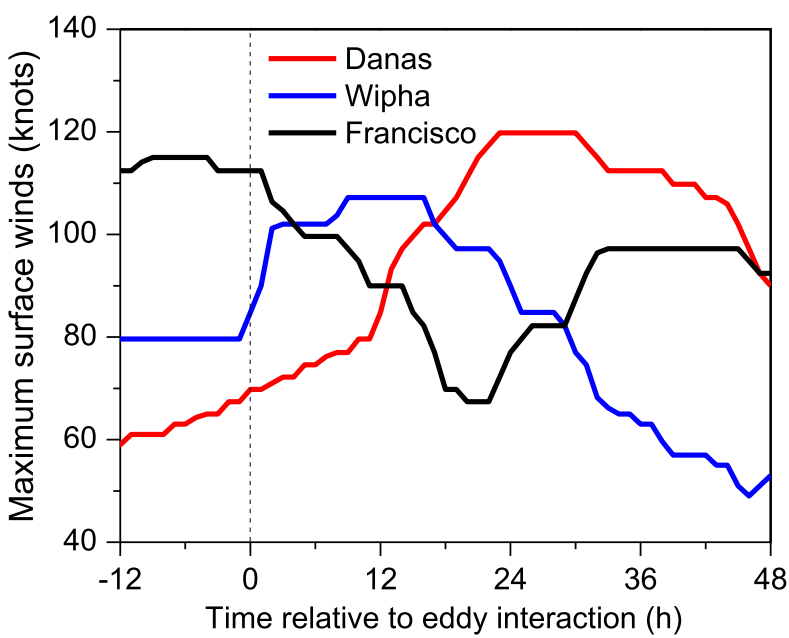

FIG. 5. The maximum surface wind speed (kt) of Typhoons Danas, Wipha, and Francisco as a function of time with respect to the interaction with the cold-core eddy. Time 0 denotes the closest approach of each typhoon to the eddy center.

center. To avoid abrupt variable gradients, the area within radii of $2.0^{\circ}-2.5^{\circ}$ from the eddy center is smoothed by linear interpolation. An experiment with an eddy radius of $1.5^{\circ}$ gives consistent results with quantitative differences (not shown). Figure 8 displays the initial SST field for COUP and NOED as well as their difference. The eddyremoved field shows mostly larger SST than the default initial field in the eddy regime, with a small area of smaller SST to the south of the eddy (Fig. 8c). An uncoupled experiment is also conducted and denoted as UNCP, using the initial SST field of NOED as the boundary conditions. All the modeled data are saved at intervals of $1 \mathrm{~h}$. The observational data used for simulation verifications include 1) the satellite-derived ADT dataset; 2) best track data from Joint Typhoon Warning Center (JTWC), China Meteorological Agency (CMA), and Japan Meteorological Agency (JMA); 3) satellite imageries from the Naval Research Laboratory; 4) horizontal surface wind structure based on the CIRA/CIMSS product; and 5) daily SST data at a resolution of $\sim 9 \mathrm{~km}$ from Remote Sensing Systems (RSS) microwave and infrared optimally interpolated SST product.

\section{b. Verification of simulation and intensity change}

The simulated outgoing longwave radiation (OLR) at the top of the atmosphere in COUP is shown in Figs. $6 \mathrm{~g}$ and $6 \mathrm{~h}$ as an indication of convection activities. Low values of OLR imply deep cloud in which longwave radiation cannot fully penetrate. Prior to the RW, both the simulations and observations display symmetric and compact eyewall structure with a tiny eye, as well as two primary rainbands in the north and south of the typhoon.
The primary characteristics are similar to those from observations. After the RW, the model reproduces the remarkably broadened eye size and the disorganized eyewall convection, though with some detailed difference in the asymmetry of eyewall structure. The simulated peak surface wind also displays weaker values in the south of the typhoon as do the observations (Fig. 7).

Figure 9 shows the time evolution of storm intensity in terms of minimum sea level pressure and maximum 10-m surface wind, for comparisons between simulations and observations. The ADT data are shown at 1-h interval as the simulations, while the best track data of JTWC, CMA, and JMA are at intervals of $6 \mathrm{~h}$. Note that there are large discrepancies among the data sources from different regional typhoon forecast centers, since different wind speed definitions and satellite estimation methods have been used (Nakazawa and Hoshino 2009; Harper et al. 2010; Knapp and Kruk 2010; Knapp et al. 2013). There are also other best track sources included in the International Best Track Archive for Climate Stewardship (IBTrACS; https://www.ncdc.noaa.gov/ibtracs/ index.php?name=ibtracs-data). The simulated storm in COUP shows an initially slow intensification of roughly $12 \mathrm{~h}$ and then undergoes a long weakening period to the end of the simulation. Comparisons with the ADT and best track data show that the RW of Francisco has been basically reproduced by COUP, though with quantitatively differences among different data sources. The intensity evolution in NOED parallels with that in COUP first and then shows larger intensity with the storm center approaching the eddy region in COUP (Table 1). The largest intensity discrepancy between COUP and NOED occurs after the storm passing over the eddy center $(32 \mathrm{~h})$, consistent with the idealized simulation in Ma et al. (2013), being about $9 \mathrm{hPa}$ in minimum sea level pressure and $12 \mathrm{~m} \mathrm{~s}^{-1}$ in maximum surface wind at $42 \mathrm{~h}$. After moving out from the eddy region, the intensity discrepancy of two runs decreases gradually. This is as expected since the eddy is a transient feature affecting the typhoon (Ma et al. 2013). Without the negative ocean feedback, the storm in UNCP is more intense than that in the other two runs, with a central pressure difference of $19 \mathrm{hPa}$ and wind difference of $15 \mathrm{~m} \mathrm{~s}^{-1}$ from NOED at $49 \mathrm{~h}$.

One crucial difference among three experiments is the time window of RW. Following the RW definition in DeMaria et al. (2012), the onsets of RW are 13, 28, and $49 \mathrm{~h}$ for COUP, NOED, and UNCP, respectively. This indicates that the presence of cold-core eddy renders the $\mathrm{RW}$ event occurring in advance for $15 \mathrm{~h}$, while the cold wake tends to be more significant in leading to the RW 

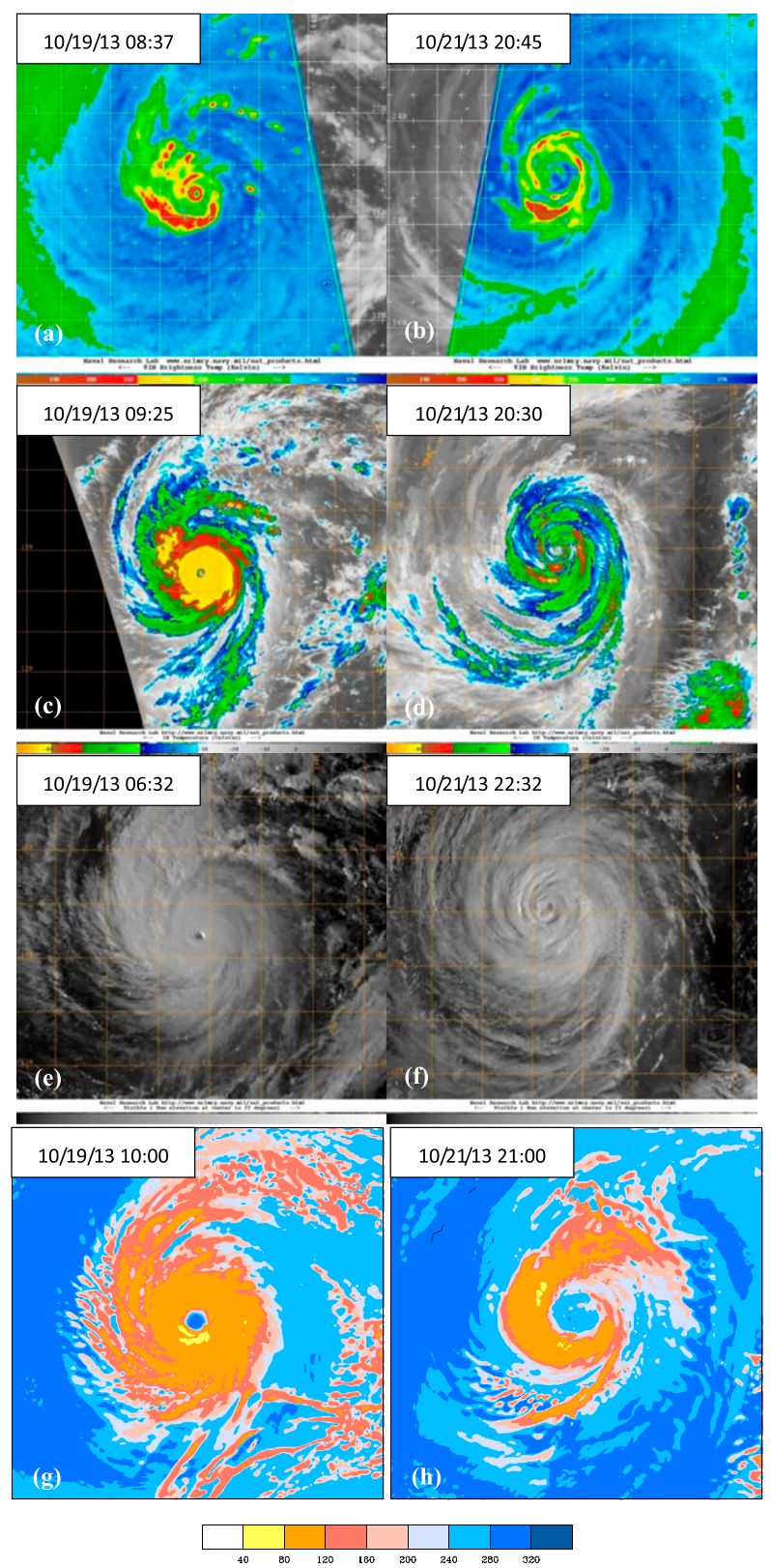

FIG. 6. Satellite images of (a),(b) $91 \mathrm{H}$ brightness temperature $(\mathrm{K}),(\mathrm{c}),(\mathrm{d})$ infrared temperature $\left({ }^{\circ} \mathrm{C}\right),(\mathrm{e}),(\mathrm{f})$ visible images, and $(\mathrm{g}),(\mathrm{h})$ simulated images of outgoing longwave radiation (OLR; $\mathrm{W} \mathrm{m}^{-2}$ ) from COUP experiment, with times given at the top of each panel. (Images provided courtesy of the Naval Research Laboratory in Monterey, CA.)

of Francisco. Even so, the intensity decrease induced by the eddy is comparable to that of the cold wake during storm-eddy interaction, suggesting that the cold-core eddy has played an important role in contributing to the RW of Francisco. From Table 1, the averaged translation speed during the storm-eddy interaction is $3.6-3.7 \mathrm{~m} \mathrm{~s}^{-1}$, which is relatively slow but still much faster than that in Walker et al. (2014), in which Hurricane Kenneth translated rather slowly with a speed below $1.5 \mathrm{~m} \mathrm{~s}^{-1}$. This suggests that the open-ocean, cold-core eddies could contribute to RW of TCs even when they translate at a medium speed.

Figure 10 displays storm tracks at 1-h interval from simulations and ADT dataset, superimposed with sea level height at the initial time of simulation (19 October) and the location of the eddy interacting with Francisco. The JTWC, CMA, and JMA tracks are not shown because of their coarse temporal resolution and similarity to the ADT track. All three experiments capture the typhoon track reasonably well, suggesting that the track is little affected by ocean coupling as confirmed in previous studies (e.g., Wu et al. 2005). The cold-core eddy of interest is characterized by relatively low sea surface height, located right below simulated storm tracks.

Environmental vertical wind shear puts a strong control on the intensity of TCs; weak vertical wind shear is commonly considered to be favorable for the intensification of TCs (Kaplan and DeMaria 2003; Kaplan et al. 2010; Wang et al. 2015). As consistent reflected from the observations (Figs. 2d,f), The vertical wind shear is strong at the initial time of simulation (Fig. 11a) when the storm intensity is intense, and then it decreases steadily to less than $3 \mathrm{~m} \mathrm{~s}^{-1}$ at $72 \mathrm{~h}$ and increases afterward in a slight extent. Therefore, weakening vertical wind shear during the RW stage indicates that it cannot be a main contributor to the simulated RW of Francisco. This is different from the case of Hurricane Kenneth, in which the strong vertical wind shear also contributed to the weakening of the TC (Pasch 2006; Walker et al. 2014). The midlevel dry air is another atmospheric factor that may affect the intensity of TCs (Ge et al. 2013). The evolution of simulated midlevel humidity, calculated by averaging the relative humidity between 850 and $650 \mathrm{hPa}$ following Ge et al. (2013), shows that the environmental humidity varies within a range of $55 \%-65 \%$ throughout the simulation, with little difference among three experiments (Fig. 11b). The relatively high environmental humidity indicates that the intrusion of dry air cannot be the reason for the RW of Francisco.

The ocean heat content ( $\mathrm{OHC})$, as a measurement of subsurface ocean structure, is closely related to the intensity change of TCs (e.g., Hong et al. 2000; Mainelli et al. 2008; Kaplan et al. 2010). It is defined by Leipper and Volgenau (1972) with the following form:

$$
\mathrm{OHC}=\int_{0}^{\mathrm{H} 26} \rho c_{p}(T-26) d h
$$


(a) WP2613 FRANCISCO 201321 Oct OOUTC

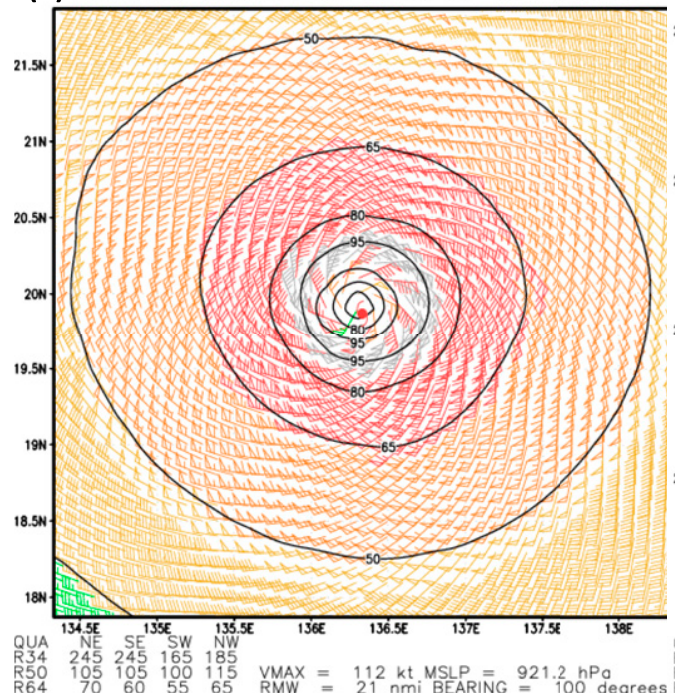

(c) 201321 oct 00UTC for COUP

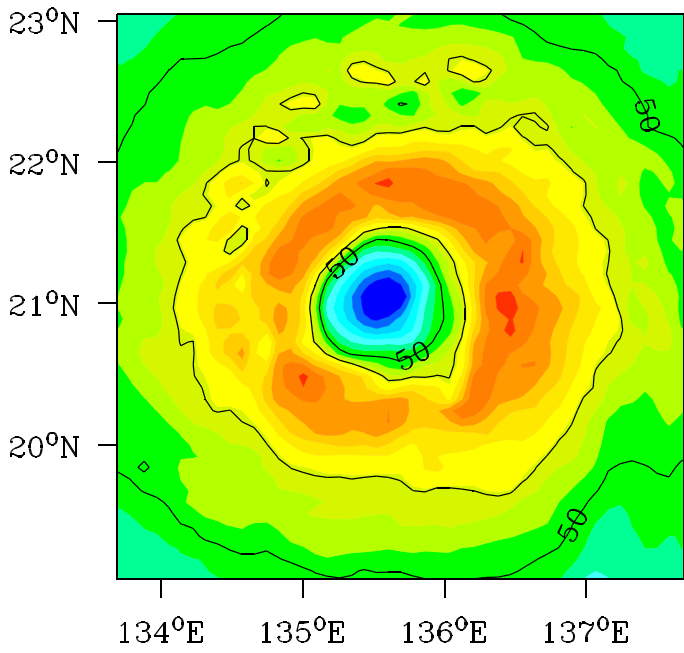

(b) WP2613 FRANCISCO 201321 Oct 18UTC

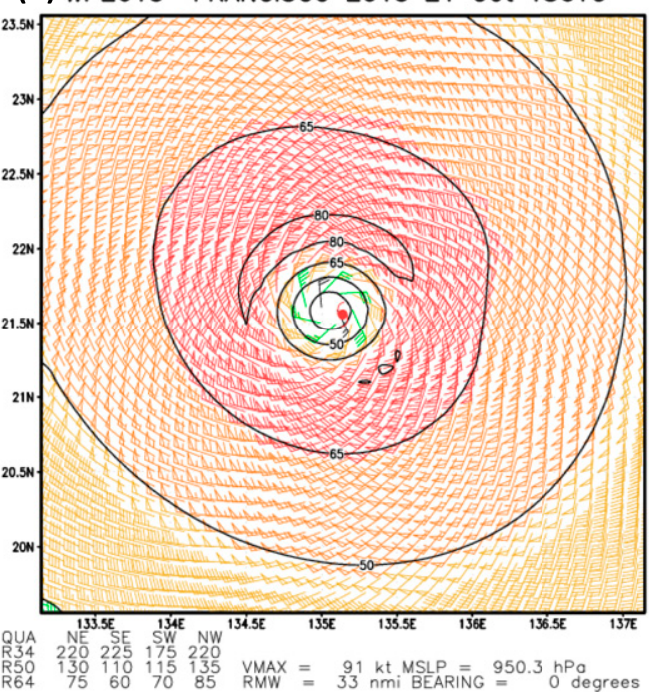

(d) 201321 Oct 18UTC for COUP

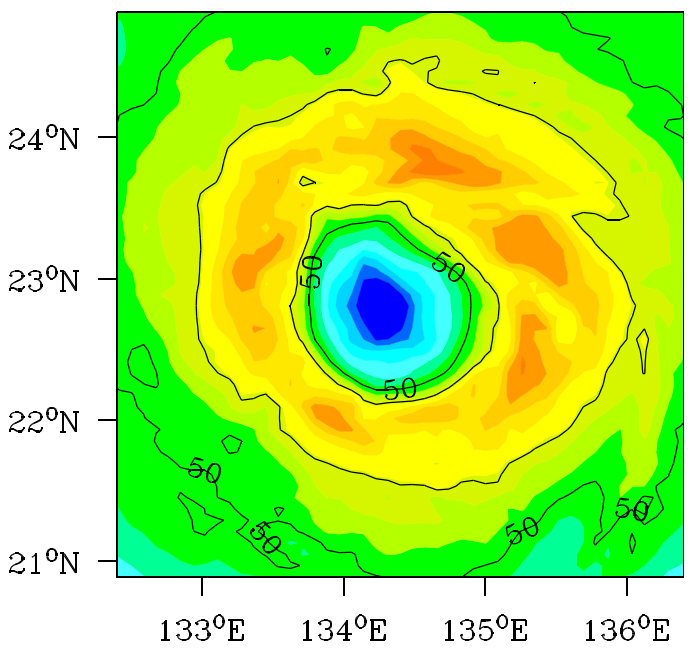

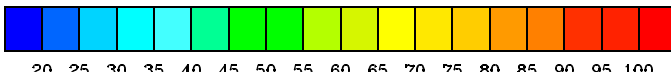

FIG. 7. Plan views of (a),(b) satellite-derived and (c),(d) simulated surface wind speed (kt) at (a),(c) 0000 UTC 21 Oct and (b),(d) 1800 UTC 21 Oct 2013. Black contours in (c) and (d) denote radii of 50 and 64 kt. The observed horizontal surface wind plots of (a) and (b) are obtained from http://rammb.cira.colostate.edu/products/ tc_realtime/storm.asp?storm_identifier $=$ WP262013.

where $\mathrm{H} 26$ is the depth $(\mathrm{m})$ of the $26^{\circ} \mathrm{C}$ isotherm, $\rho$ is the ocean density taken as $1 \mathrm{~g} \mathrm{~cm}^{-3}, c_{p}$ is specific heat at constant pressure taken as $4.2 \mathrm{~kJ} \mathrm{~kg}^{-1} \mathrm{~K}^{-1}, T$ is the ocean temperature $\left({ }^{\circ} \mathrm{C}\right)$, and $26^{\circ} \mathrm{C}$ is commonly recognized as the minimum SST beneficial for TC intensification. ${ }^{1}$

\footnotetext{
${ }^{1}$ Observations have shown that TCs can develop with SST below $26^{\circ} \mathrm{C}$ (Dare and McBride 2011b; McTaggart-Cowan et al. 2015).
}

Figure $11 \mathrm{c}$ shows the evolution of prestorm OHC along the simulated storm track in COUP and NOED. The initial $\mathrm{OHC}$ is larger than $30 \mathrm{~kJ} \mathrm{~cm}^{-2}$, which is favorable for the intensification. However, the $\mathrm{OHC}$ in COUP decreases sharply to less than $10 \mathrm{~kJ} \mathrm{~cm}^{-2}$ with storm approaching the cold-core eddy, thus being detrimental for the storm intensification. From about 12 to $60 \mathrm{~h}$, the OHC in NOED tends to be much larger than that in COUP due to the removal of the eddy; as a 
(a) COUP

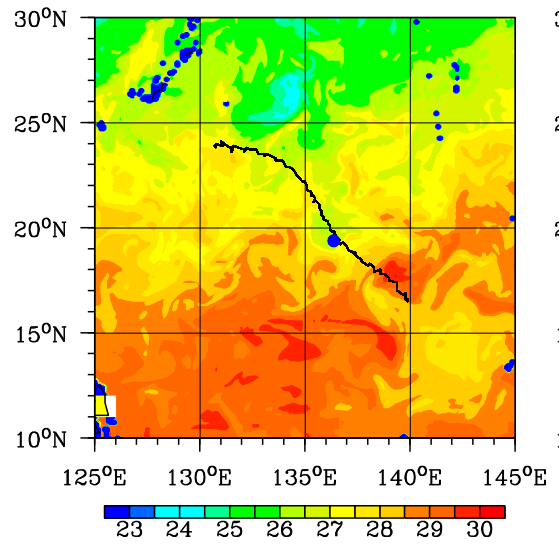

(b) NOED

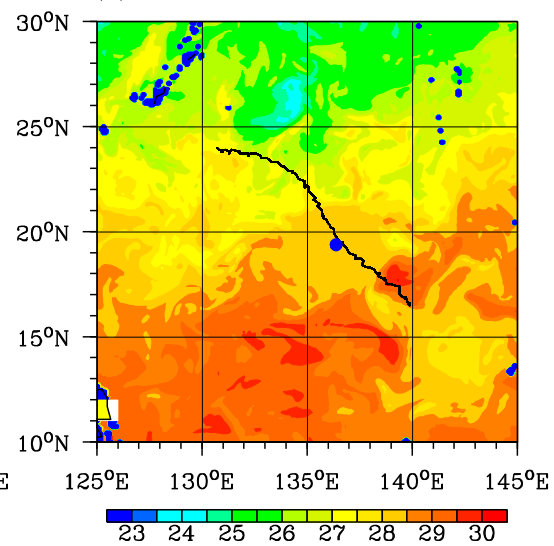

(c) COUP-NOED

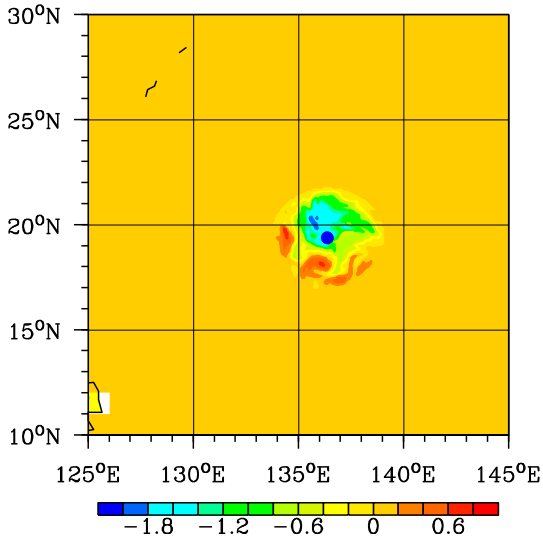

FIG. 8. Plan views of the initial SST field on 19 Oct for (a) COUP and (b) NOED (also UNCP), and (c) SST difference between COUP and NOED. The simulated 1-h storm tracks of COUP and NOED are also included in (a) and (b), respectively.

result, its storm is more intensified during this time period. The consistent evolutionary trend between the storm intensity and the prestorm OHC for COUP and NOED suggests that the presence of cold-core eddy is crucial for the RW occurence of Francisco. From Fig. 11d, the cold-core eddy strengthens sea surface cooling evidently. At $42 \mathrm{~h}$ the area-averaged SST in COUP is about $1{ }^{\circ} \mathrm{C}$ smaller than that in NOED, which is comparable to the SST decrease of $1.2^{\circ} \mathrm{C}$ induced by cold wake, measured by the difference between COUP and UNCP. This suggests that the cold-core eddy is responsible for approximately half of the sea surface cooling during storm-eddy interaction.
The relatively favorable atmospheric environment with decreasing shear and absence of dry-air intrusion while dramatic ocean response indicate that the RW of Francisco could be largely attributed to the dramatic changes in ocean conditions induced by the typhoon.

Figure 12 displays the SST distribution on 21 October by observation and simulations of COUP and NOED. The simulated SST is averaged between 24 and $42 \mathrm{~h}$ at a 6-h interval. A comparison between the observation and the COUP simulation shows that the atmosphere-ocean coupled model can reproduce the storm-induced SST response reasonably well. (a) Minimum sea level pressure $(\mathrm{hPa})$

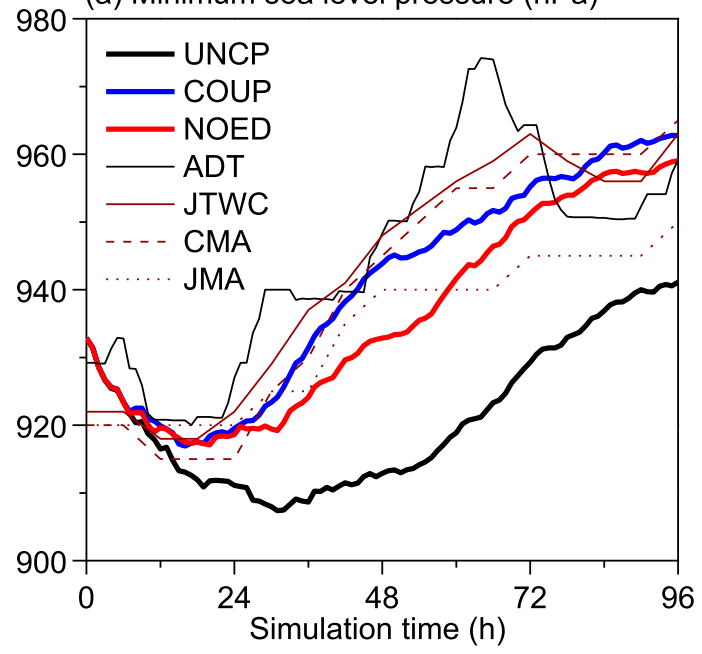

(b) Maximum surface wind speed $\left(\mathrm{m} \mathrm{s}^{-1}\right)$

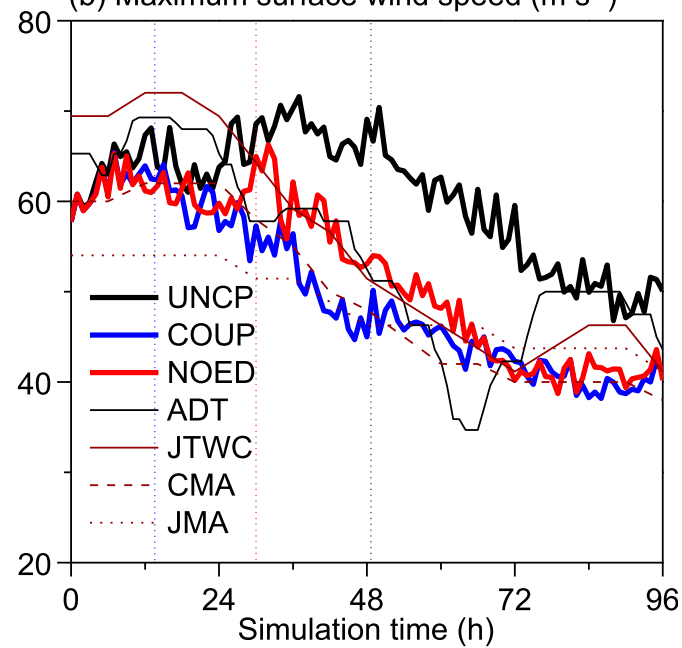

FIG. 9. Time evolution of simulated and observed (a) minimum central pressure ( $\mathrm{hPa}$ ) and (b) maximum surface wind $\left(\mathrm{m} \mathrm{s}^{-1}\right)$ by experiments UNCP, COUP and NOED and by ADT, JTWC, CMA, and JMA datasets. The ADT data are shown at a 1-h interval and the JTWC, CMA, and JMA best track data are at intervals of $6 \mathrm{~h}$. The vertical dashed lines indicate onsets of rapid weakening in each experiment: $13 \mathrm{~h}$ for COUP, $28 \mathrm{~h}$ for NOED, and $49 \mathrm{~h}$ for UNCP. 
TABLE 1. Time period for the typhoon-eddy interaction. R33 indicates the radius of $33 \mathrm{~m} \mathrm{~s}^{-1}$ (i.e., hurricane-force) winds.

\begin{tabular}{cccc}
\hline Interaction & Begin $(\mathrm{h})$ & End $(\mathrm{h})$ & $\begin{array}{c}\text { Translation } \\
\text { speed }\left(\mathrm{m} \mathrm{s}^{-1}\right)\end{array}$ \\
\hline $\begin{array}{c}\text { Storm center interacts } \\
\text { with eddy }\end{array}$ & 17 & 48 & 3.6 \\
\begin{tabular}{l} 
R33 interacts with eddy \\
\hline
\end{tabular} & 11 & 57 & 3.7 \\
\hline
\end{tabular}

One distinguished feature is that there is a nearcircular cooling of sea surface around the eddy, which is a typically amplified SST response induced by the cold-core eddy (Ma et al. 2013). The minimum SST value in the cooling area is well below the threshold of $26^{\circ} \mathrm{C}$, being even smaller than the surface-layer temperature (will be shown in Fig. 14), which therefore cannot sustain the intensity of Francisco. Since the storm center has crossed over the eddy (Fig. 10), the cold-core eddy is capable of affecting the eye and eyewall structure directly. Both observations and simulations evidence that the eye size is broadened evidently accompanying the weakening of the storm as it encounters the eddy (Fig. 6). The only difference of SST distribution between COUP and NOED is that the near-circular sea surface cooling is absent in NOED by removing the eddy, with a cold wake feature left along the storm track because of upwelling, entrainment, and shear-induced vertical mixing in the upper ocean (e.g., Price 1981; Yablonsky and Ginis 2009; Shay 2010).

\section{c. Air-sea interaction}

The eddy-induced changes in upper-ocean response are examined by the difference of ocean temperature and vertical motion between COUP and NOED (Fig. 13). The ocean water below the storm tends to become cooler as the storm approaches the regime of cold-core eddy (Fig. 13a). The coolest core of ocean water is located at a depth of $40 \mathrm{~m}$, at $\sim 36 \mathrm{~h}$ when the storm center crosses over the eddy center. After $\sim 48 \mathrm{~h}$ the cooler water vanishes gradually as the storm leaves the eddy region. The ocean vertical velocity is mostly weaker in COUP than that in NOED, since the storm intensity is overall weaker in COUP throughout the simulation (Fig. 9). Nonetheless, the upward motion is evidently stronger in the eddy regime of COUP, indicating that the cold-core eddy has boosted the oceanic response to the typhoon. Therefore, it is the combined effect of cooler water and stronger upward motion that contributes to larger SST response in the eddy regime.

The direct contribution of cold-core eddy to the intensity change of TCs is accomplished by modulating the

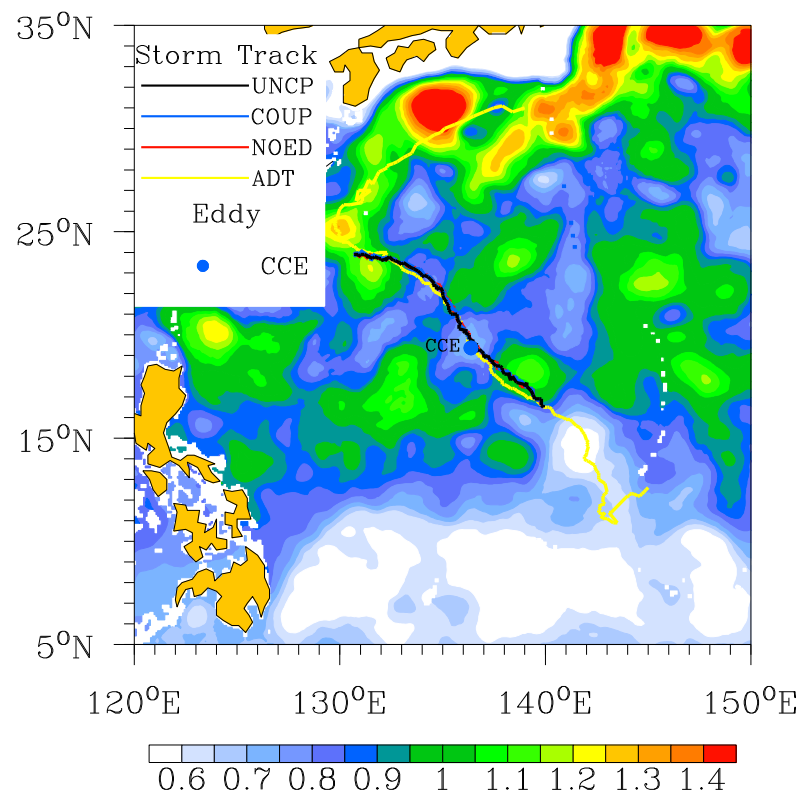

FIG. 10. A spatial map of simulated tracks by UNCP, COUP, and NOED, and observed ADT track for the whole life of Francisco. The sea level height $(\mathrm{m})$ at the initial time of simulation (19 Oct) based on HYCOM+NCODA data is also superimposed, with the location of the cold-core eddy (CCE) of interest being marked by blue dot.

sea-to-air enthalpy flux as atmospheric response to SST decrease. The bulk formulas of surface latent heat flux (LHX) and surface sensible heat flux (SHX) are as follows:

$$
\begin{aligned}
& \mathrm{LHX}=\rho L_{v} C_{q} U_{a}\left(q_{s}-q_{a}\right), \\
& \mathrm{SHX}=\rho c_{p} C_{h} U_{a}\left(\theta_{s}-\theta_{a}\right),
\end{aligned}
$$

where $\rho$ is air density in the surface layer; $L_{v}$ is the latent heat of vaporization; $c_{p}$ is specific heat at constant pressure; $U$ is horizontal wind speed; $C_{q}$ and $C_{h}$ are surface exchange coefficients for moisture and heat, respectively; $q$ is water vapor mixing ratio; and $\theta$ is potential temperature. The subscripts $a$ and $s$ signify the surface layer (the lowest model level) and the bottom surface, respectively. The SST response is primarily responsible for the moisture and thermal disequilibrium at the air-sea interface. Therefore, the Hovmöller diagrams of LHX and SHX, air-sea moisture and thermal difference, and $q_{s}$ and $\theta_{s}$ are diagnosed in Fig. 14 for the COUP experiment. Note that SHX is less effective than LHX in fueling the storm intensification, while it could be instrumental for maintaining rainband activities (Ma et al. 2015; Ma 2018).

The peak LHX in COUP is about $1000 \mathrm{~W} \mathrm{~m}^{-2}$ roughly in the first $12 \mathrm{~h}$, which contributes to a short-time 
(a) Vertical wind shear $\left(\mathrm{m} \mathrm{s}^{-1}\right)$

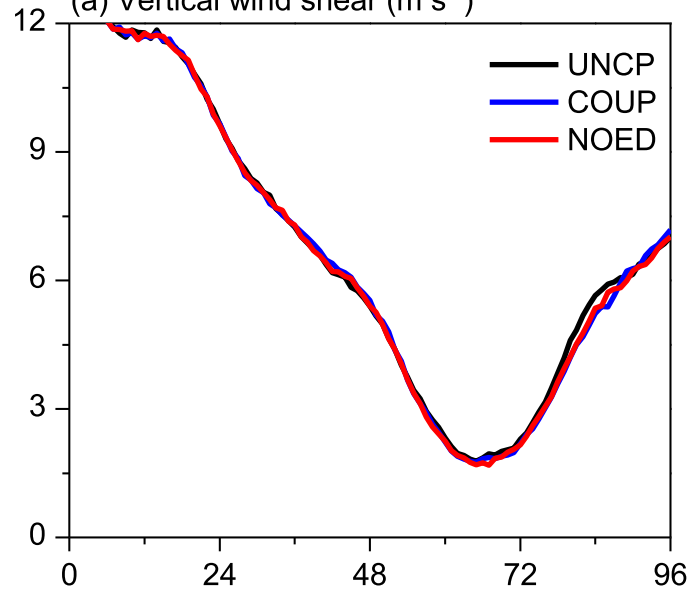

(c) Initial $\mathrm{OHC}\left(\mathrm{kJ} \mathrm{cm}^{-2}\right)$

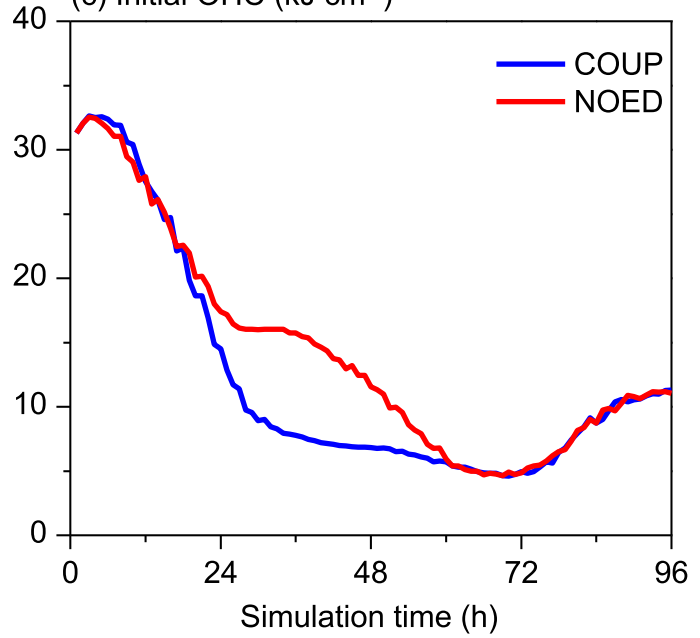

(b) Midlevel humidity (\%)

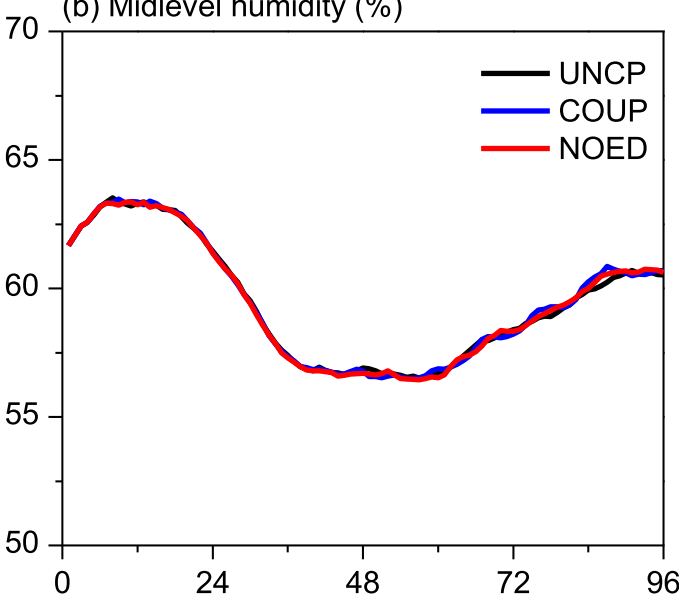

(d) Inner-core SST ( $\left.{ }^{\circ} \mathrm{C}\right)$

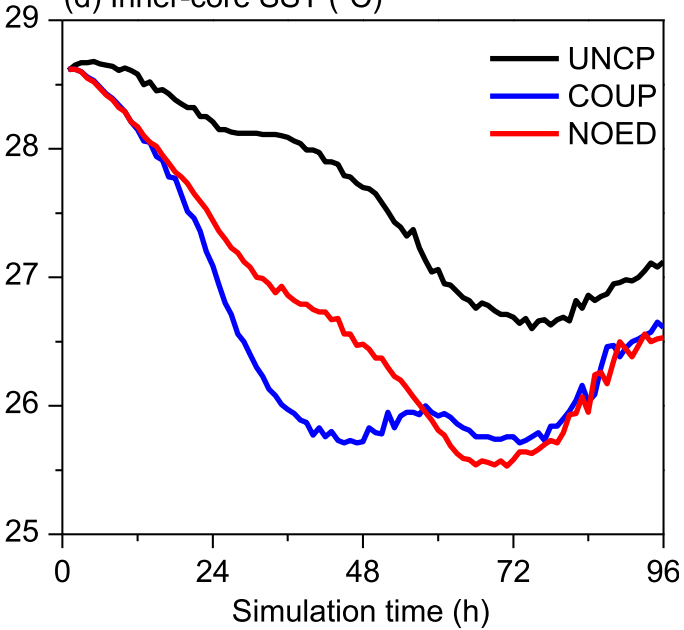

FIG. 11. Time evolution of (a) environmental 850-200-hPa vertical wind shear ( $\mathrm{m} \mathrm{s}^{-1}$ ), (b) 850-600-hPa-averaged midlevel humidity (\%), (c) area-averaged initial-field ocean heat content $\left(\mathrm{kJ} \mathrm{cm}^{-2}\right)$, and (d) area-averaged SST $\left({ }^{\circ} \mathrm{C}\right)$. The $850-200-\mathrm{hPa}$ vertical wind shear and midlevel humidity is calculated within radii of $300-800 \mathrm{~km}$ relative to the storm center. The oceanic heat content and inner-core SST is calculated along simulated storm tracks within a radius of $200 \mathrm{~km}$ from the storm center. Note that in (d) the SST in UNCP is fixed, but it varies in COUP and NOED due to oceanic response.

intensification of Francisco (Fig. 9). As the simulated storm begins to interact with the cold-core eddy, both LHX and SHX decrease rapidly with time. After the time when the storm center passes over the eddy center $(32 \mathrm{~h})$, the LHX is as dramatically small as $200 \mathrm{~W} \mathrm{~m}^{-2}$. An examination of the sea-air moisture difference (Fig. 14b) suggests that it is the diminishing moisture disequilibrium that results in a substantial decrease of LHX supply. The magnitude of moisture disequilibrium is largely determined by the ground saturated mixing ratio $q_{s}$, rather than by specific humidity in the surface layer (Jaimes et al. 2015). Since the ground saturated mixing ratio is positively related to SST, the remarkable decrease in $q_{s}$ (Fig. 14c) is associated with the cooling effect of the cold-core eddy.
The pronounced sea surface cooling not only cuts down the supply of LHX, but also reduces the sea-air thermal disequilibrium. A notable feature is that the surface layer is even warmer than the sea surface due to the presence of cold-core eddy, as indicated by the area of negative values in Fig. 14e. This consequently leads to negative values of SHX (Fig. 14d), suggesting that the surface layer transfers heat downward to the ocean in the eddy regime. Following Francisco's passage over the coldcore eddy, there is little supply of SHX. The absence or even downward transfer of SHX may stabilize the boundary layer, which will be illustrated in Part II of this study.

Figure 15 shows the time evolution of all variables in Fig. 14 to compare discrepancies among three 
(a) Observed SST

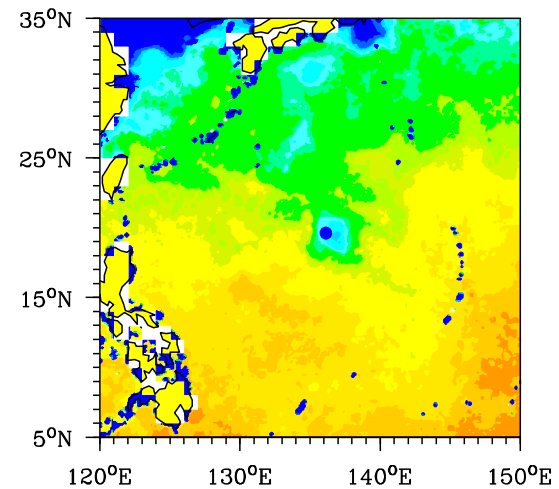

(b) Simulated SST for CoUP

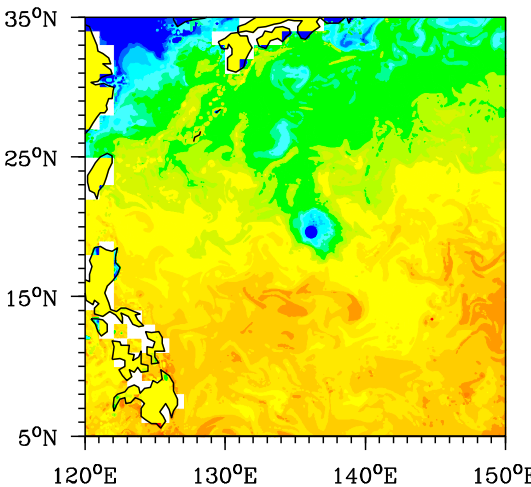

(c) Simulated SST for NOED

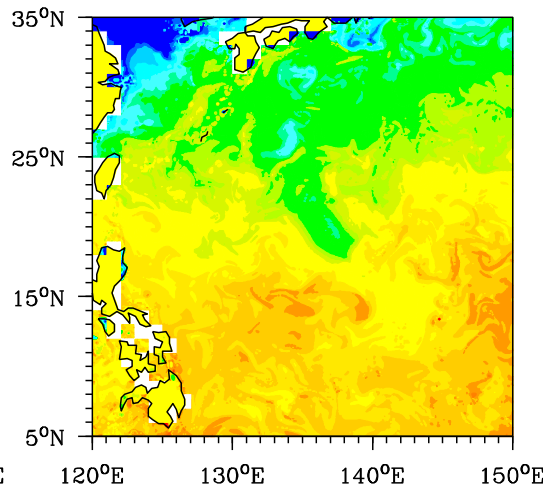

$\begin{array}{lllllllllllllllllllllll}22 & 22.5 & 23 & 23.5 & 24 & 24.5 & 25 & 25.5 & 26 & 26.5 & 27 & 27.5 & 28 & 28.5 & 29 & 29.5 & 30 & 30.5 & 31 & 31.5 & 32\end{array}$

FIG. 12. Plan views of (a) observed SST on 21 Oct from RSS microwave and infrared optimally interpolated SST $\left({ }^{\circ} \mathrm{C}\right)$ daily product, and daily averaged SST $\left({ }^{\circ} \mathrm{C}\right)$ on 21 Oct from the outermost domain of (b) COUP and (c) NOED. Blue dots in (a) and (b) denote the observed location of cold-core eddy interacting with Francisco.

experiments. All the variables show very similar behaviors as the inner-core SST evolution (Fig. 11d), indicating that the SST response largely dominates in the air-sea moisture and thermal disequilibrium as well as the transfer of surface enthalpy flux (Black et al. 2007). The effect of cold wake is shown to be long lasting since it is always below the storm, while the effect of cold-core eddy is transient, being prominent when the storm passes over it. During the storm-eddy interaction, the role of cold-core eddy in changing surface enthalpy flux is comparable to that of cold wake. Similar to the hypothesis that bursts in enthalpy fluxes caused by warm oceanic structures may lead to RI of TCs (Jaimes et al. 2015), the abrupt drop of enthalpy flux supply induced by the cold-core eddy could be one mechanism for the RW of TCs.

\section{d. Atmospheric processes}

From the energetic perspective, the inward transport of equivalent potential temperature $\theta_{e}$ is crucial (a) $\mathrm{T}$ for COUP-NOED

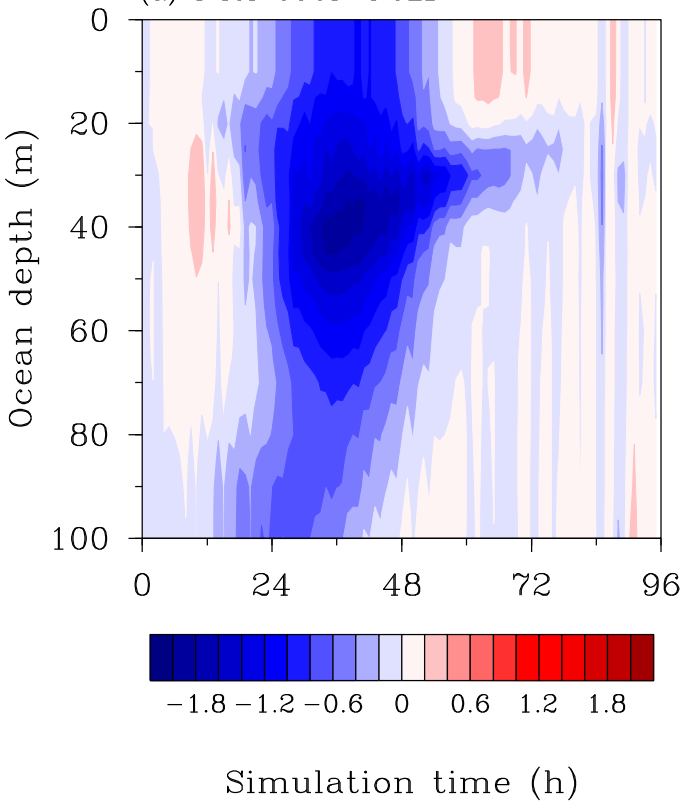

(b) W for COUP-NOED

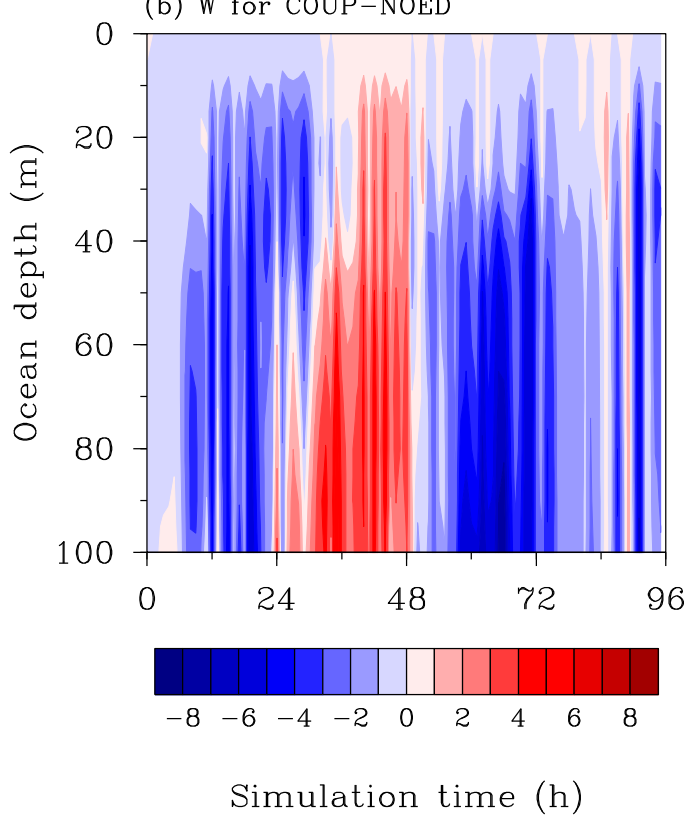

FIG. 13. Time series of area-averaged difference between COUP and NOED within a radius of $200 \mathrm{~km}$ from the storm center in the upper $100 \mathrm{~m}$ for (a) ocean temperature $\left({ }^{\circ} \mathrm{C}\right)$ and $(\mathrm{b})$ vertical velocity $\left(10^{-5} \mathrm{~m} \mathrm{~s}^{-1}\right)$. 


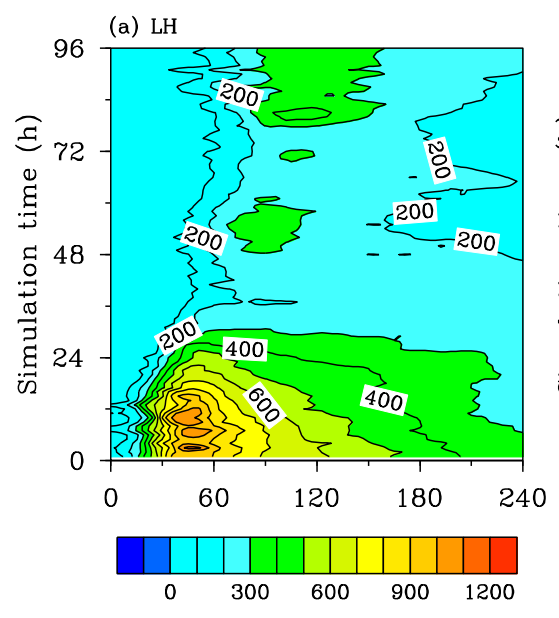

Radius $(\mathrm{km})$

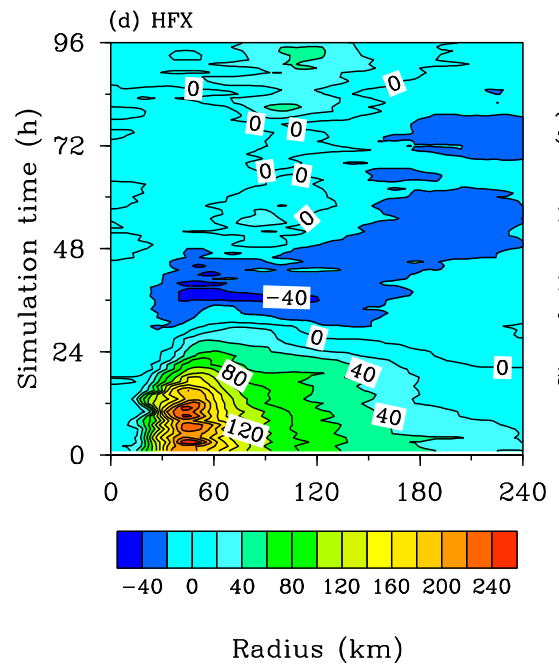

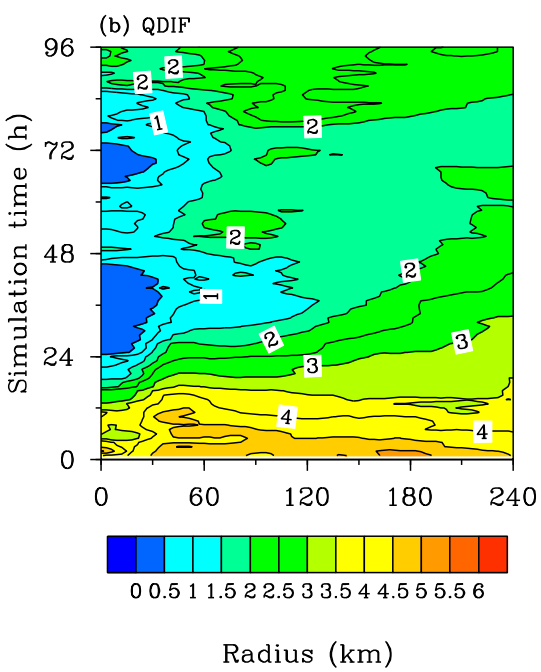
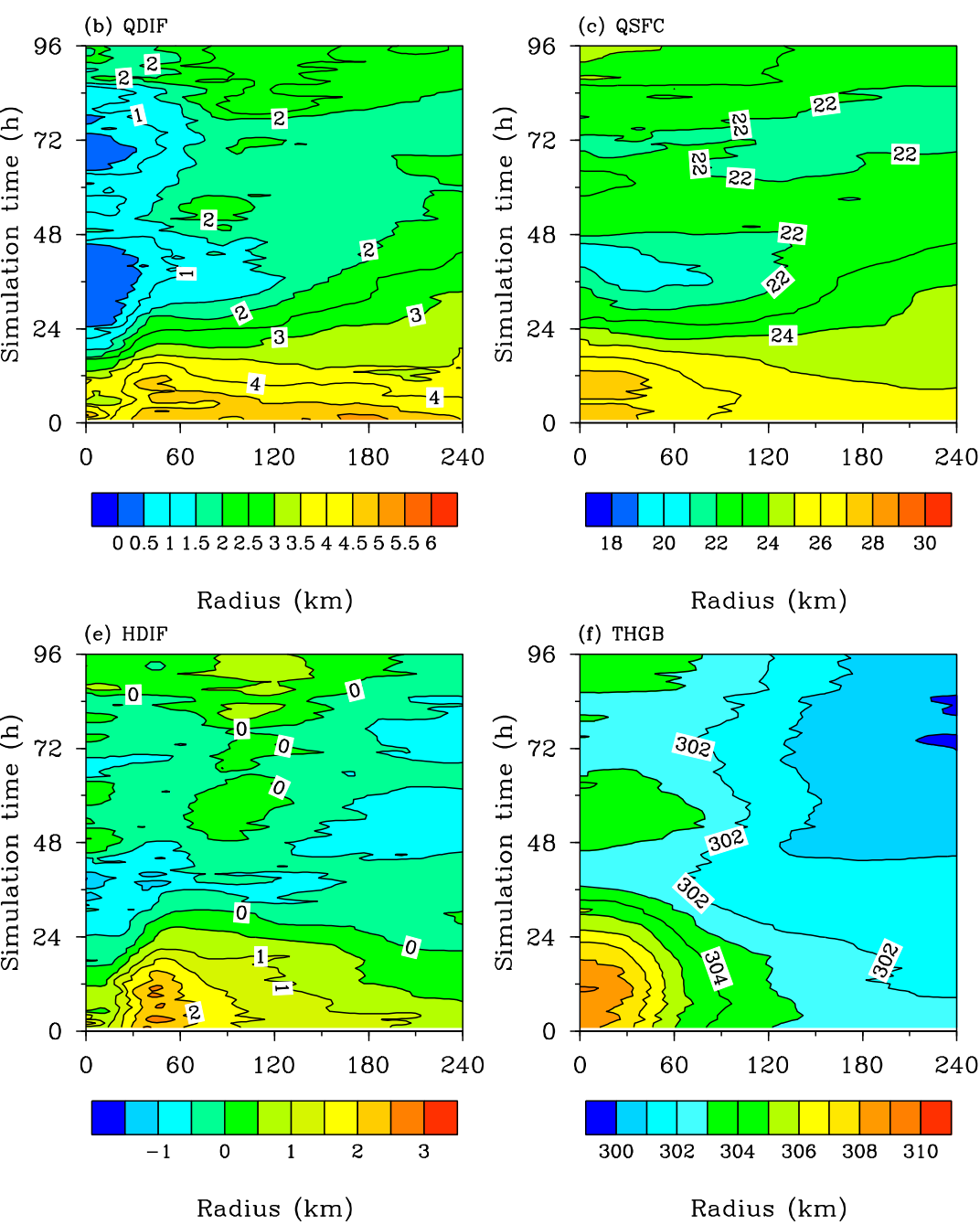

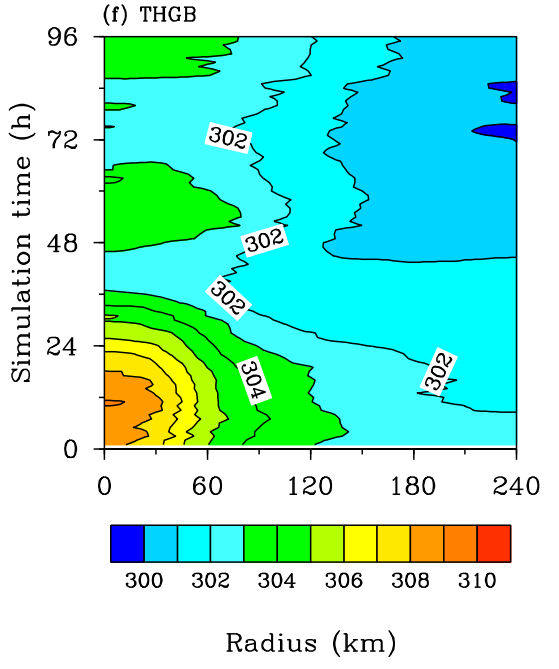

FIG. 14. Hovmöller diagram of azimuthally averaged (a) surface latent heat flux (W m$\left.{ }^{-2}\right)$, (b) $q_{s}-q_{a}\left(10^{-3} \mathrm{~kg} \mathrm{~kg}^{-1}\right),(\mathrm{c}) q_{s}\left(10^{-3} \mathrm{~kg} \mathrm{~kg}^{-1}\right)$, (d) surface sensible heat flux $\left(\mathrm{W} \mathrm{m}^{-2}\right)$, (e) $\theta_{s}-\theta_{a}(\mathrm{~K})$, and (f) $\theta_{s}(\mathrm{~K})$ for COUP.

for fueling the convection activities of TCs. High values of $\theta_{e}$ in the low-level eye might be favorable for the intensification of TCs by eye-eyewall mixing processes (Persing and Montgomery 2003; Cram et al. 2007). The earlier theory of Malkus and Riehl (1960) and Emanuel (1986) also indicates that the drop in central pressure is positively related to the difference in $\theta_{e}$ between the storm center and the outer periphery. The dominant source for radial increase in $\theta_{e}$ comes from the sea-to-air supply of surface enthalpy flux. Figure 16 shows an example of low-level $\theta_{e}$ distribution at $24 \mathrm{~h}$ in COUP, as well as its difference from NOED at $24,30,36,42$, and $48 \mathrm{~h}$. The eye is characterized by peak value as documented in previous studies (Houze 2010). The values of $\theta_{e}$ in COUP becomes smaller than that in NOED progressively because of the decreasing supply of surface enthalpy flux, suggesting that the low-level air tends to be less energetic due to the impact of cold-core eddy. Of interest is that the $\theta_{e}$ in the eye region is distinctly smaller in COUP than that in NOED. Their difference approaches to $9 \mathrm{~K}$, and the low-value region expands when the cold-core eddy interacts with the storm consistently. The significant $\theta_{e}$ difference between COUP and NOED in the eye region due to the presence of cold-core eddy reveals a large decrease in $\theta_{e}$ gradient between the storm center and the outer periphery, corresponding well with the rapid intensity weakening in COUP as well as its weaker intensity relative to NOED.

Figure 17 shows the simulated maximum radar reflectivity at an interval of $24 \mathrm{~h}$ for UNCP, COUP, and NOED to examine the impact of eddy and cold wake on convection activities. At the early time $(24 \mathrm{~h})$, the 
(a) Surface latent heat flux $\left(\mathrm{W} \mathrm{m}^{-2}\right)$

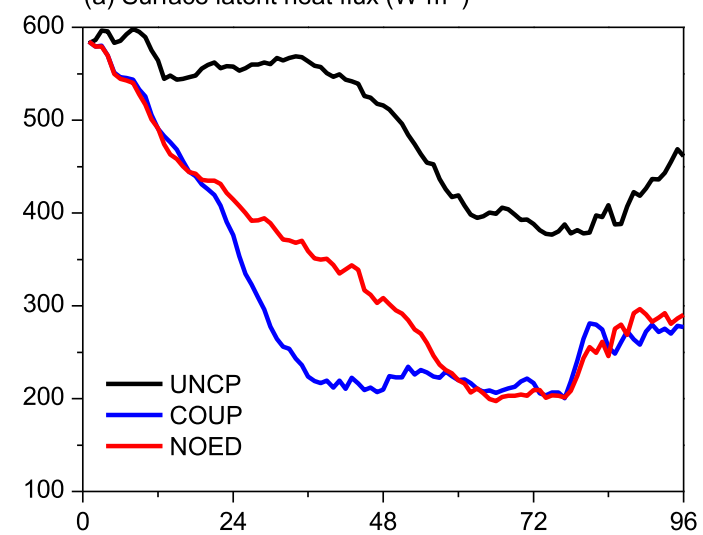

(c) $q_{s}-q_{a}\left(10^{-3} \mathrm{~kg} \mathrm{~kg}^{-1}\right)$

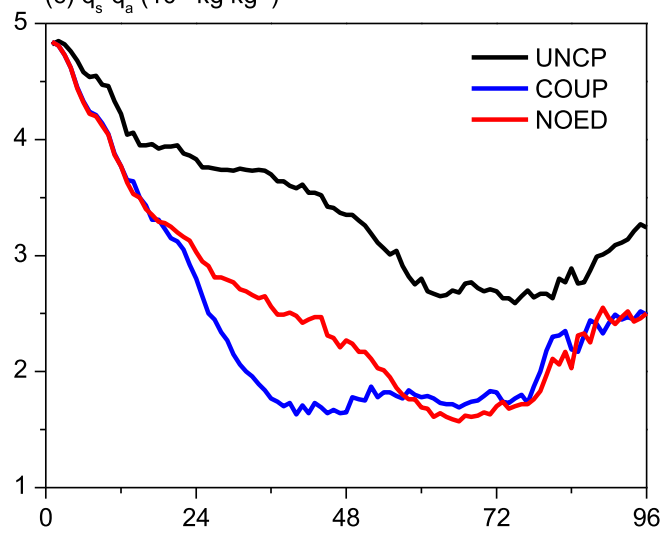

(e) $\theta_{s}-\theta_{a}(K)$

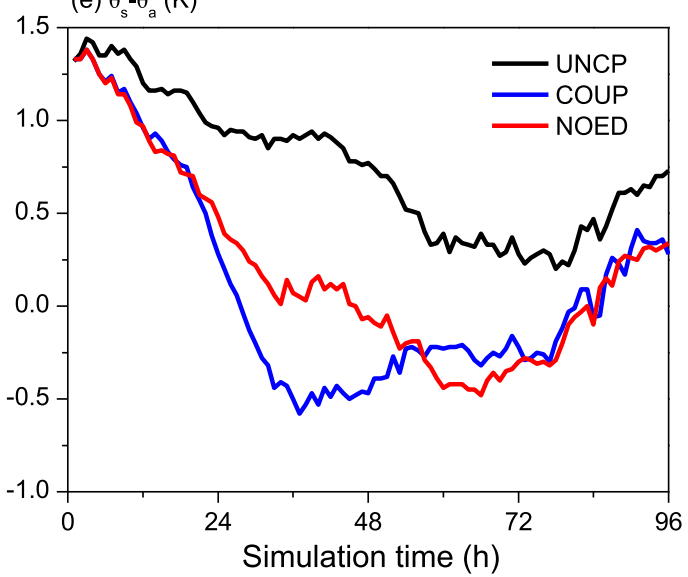

(b) Surface sensible heat flux $\left(\mathrm{W} \mathrm{m}^{-2}\right)$

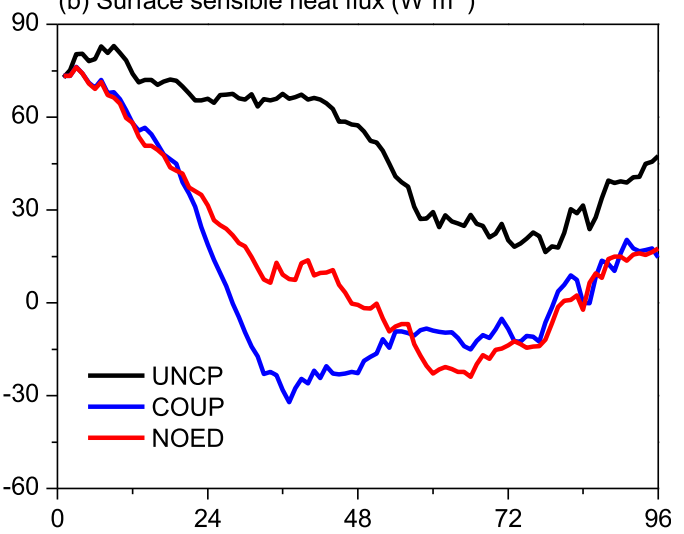

(d) $q_{\mathrm{s}}\left(10^{-3} \mathrm{~kg} \mathrm{~kg}^{-1}\right)$
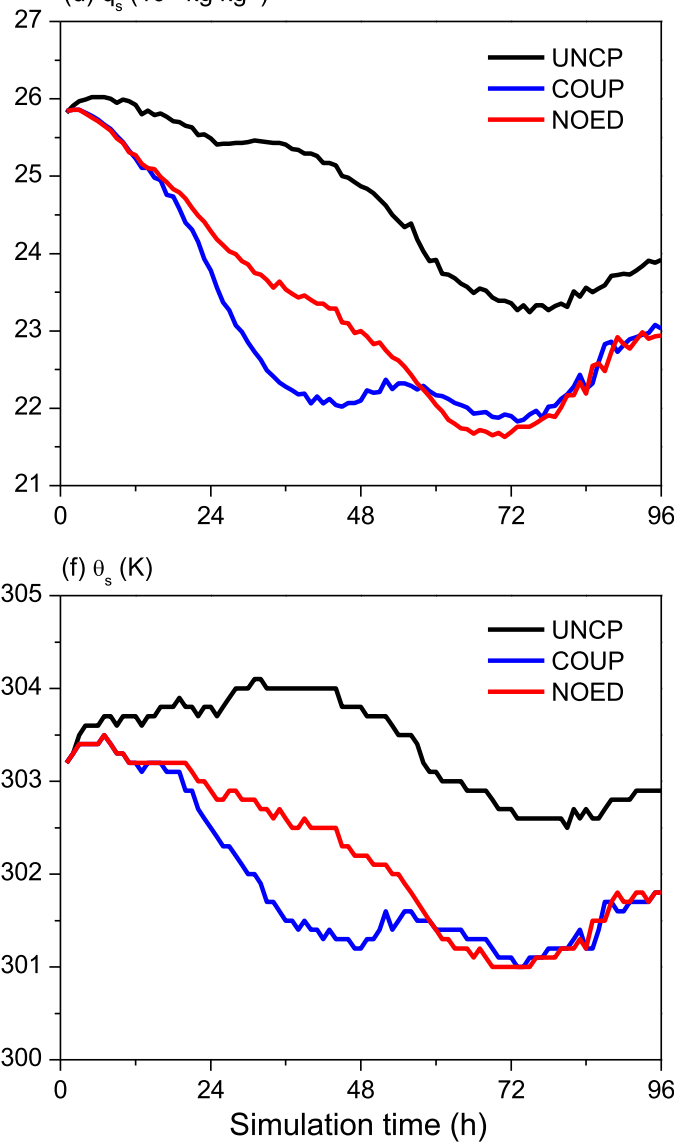

FIG. 15. Time evolution of area-averaged (a) surface latent heat flux $\left(\mathrm{W} \mathrm{m}^{-2}\right)$, (b) surface sensible heat flux $\left(\mathrm{W} \mathrm{m}{ }^{-2}\right)$, (c) $q_{s}-q_{a}\left(10^{-3} \mathrm{~kg} \mathrm{~kg}^{-1}\right)$, (d) $q_{s}\left(10^{-3} \mathrm{~kg} \mathrm{~kg}^{-1}\right)$, (e) $\theta_{s}-\theta_{a}(\mathrm{~K})$, and (f) $\theta_{s}(\mathrm{~K})$ within a radius of $200 \mathrm{~km}$ from the storm center for UNCP, COUP, and NOED.

eyewall is compact and spiral rainbands are active in all runs. Nonetheless, all three storms exhibit broadened eye size and inhibited eyewall convection accompanying the weakening (Fig. 9), but at different time periods. In COUP, the eyewall disorganization and eye broadening become apparent at $48 \mathrm{~h}$, and the convection further collapses rapidly with time evolving. The evolution from a tiny eye surrounded by compact convections to a large disorganized eye is consistent with the observation (Fig. 6). In NOED, the structural changes occur much later and to a lesser extent compared with those in COUP. This indicates 

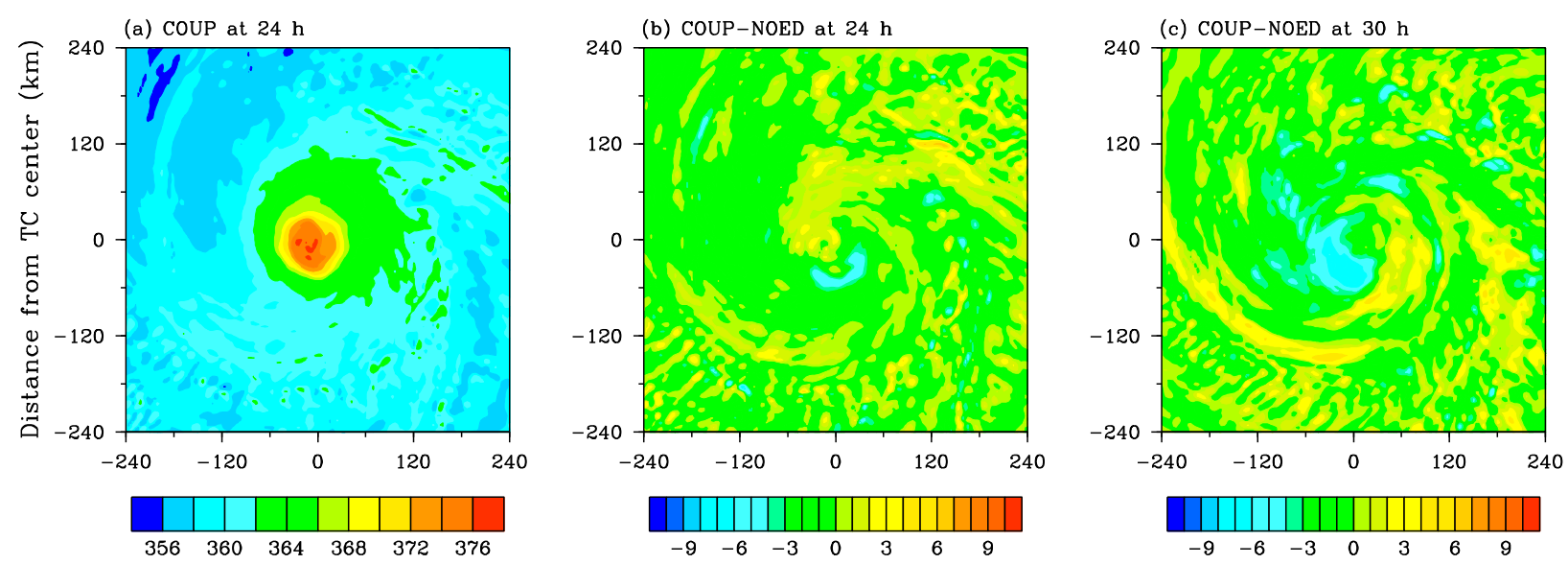

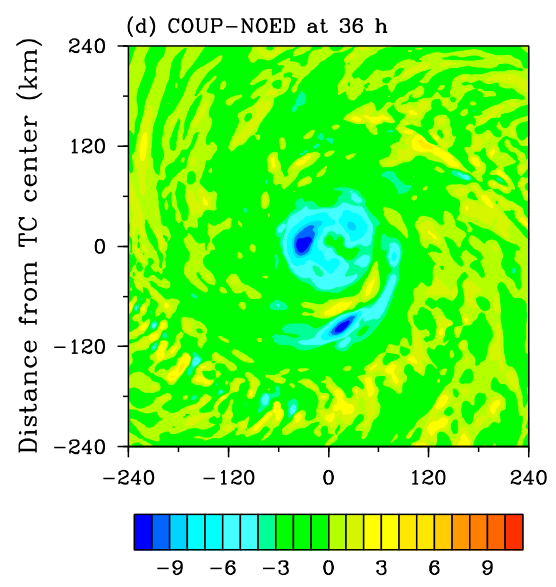

Distance from TC center $(\mathrm{km})$

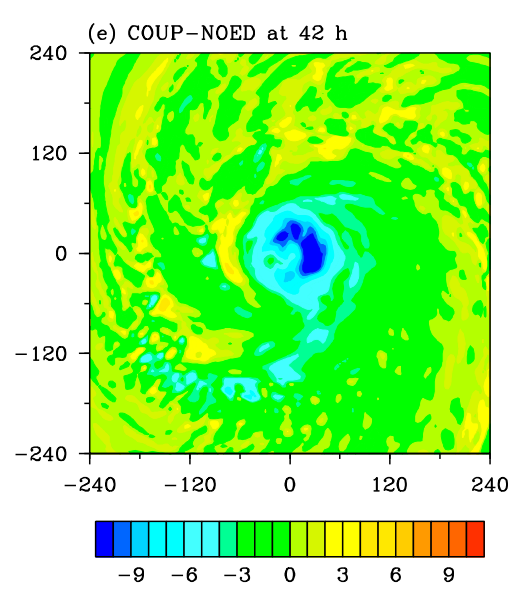

Distance from TC center $(\mathrm{km})$

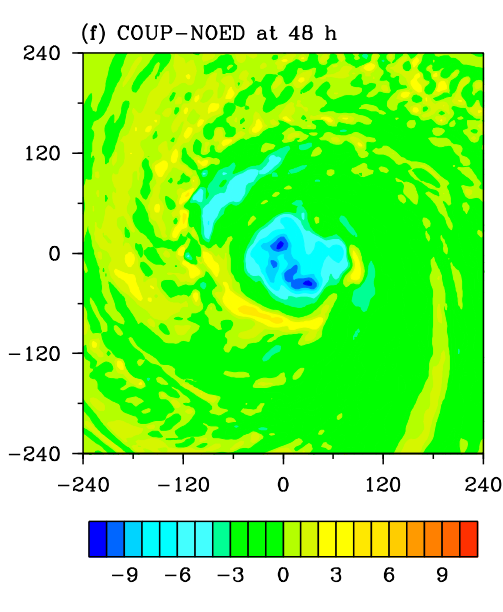

Distance from TC center $(\mathrm{km})$

FIG. 16. Plan views of depth-averaged (a) equivalent potential temperature (K) in the lowest $1 \mathrm{~km}$ of COUP, and its difference from NOED at (b) 24, (c) 30, (d) 36, (e) 42, and (f) $48 \mathrm{~h}$.

that the cold-core eddy inhibits convective activities and renders the occurrence of RW event to be earlier. A comparison of UNCP and NOED shows that the cold wake is also remarkable in leading to the collapse of convection activities, and thereby the weakening of the storm.

Previous studies have found that high- $\theta_{e}$ air in the lowlevel inner core is instrumental for fueling the development of CBs (Wang and Wang 2014), which, on the other hand, play a crucial role in the intensification of TCs, especially the RI (e.g., Guimond et al. 2010; Chen and Zhang 2013; Chang and Wu 2017). Figure 18 shows the temporal evolution and radial distribution of the numbers of $\mathrm{CBs}$, defined as the grid points where the maximum vertical motion between 4 and $15 \mathrm{~km}$ is $5 \mathrm{~m} \mathrm{~s}^{-1}$ or larger. The temporal evolution of CBs for three experiments is consistent with their intensity relationship. The CB numbers in NOED are smaller than those in UNCP throughout the simulation due to the presence of cold wake. The eddy effect on the CB activities is also discernible roughly between 24 and $48 \mathrm{~h}$, which can be reflected from their radial distribution (Fig. 18b). Within the time period when high- $\theta_{e}$ air in the eye and the eyewall is significantly reduced by interacting with the cold-core eddy (Fig. 16), the CB numbers in COUP are reduced by roughly $50 \%$ relative to those in NOED (Fig. 18b). Besides, the CBs in COUP are located at much larger radii than those in NOED. The changes in $\mathrm{CB}$ characteristics caused by the cold-core eddy may reduce the latent heat release and be displaced farther from the storm center, which can be reflected from the height-radius plots of microphysical diabatic heating (Fig. 19). Compared with that in COUP, the diabatic heating in NOED is less tilted and closer to the storm center, and the peak magnitude is nearly twice larger. There is a thin cooling layer near the surface due to rain evaporation, which has an effect of thermally stabling the boundary layer. 

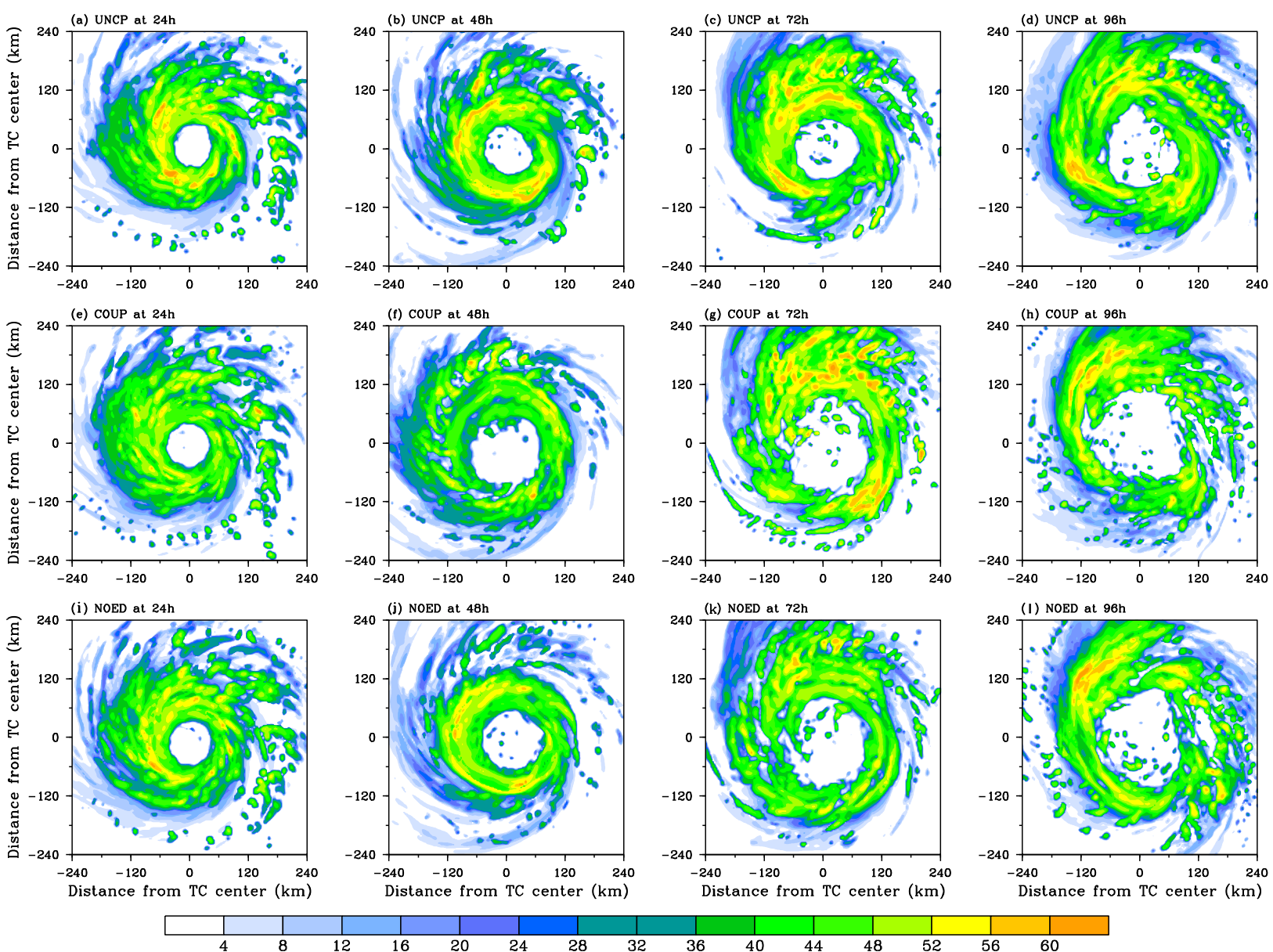

FIG. 17. Plan views of simulated maximum radar reflectivity (dBZ) for (top) UNCP, (middle) COUP, and (bottom) NOED at (a),(e),(i) 24, (b),(f),(j) 48, (c),(g),(k) 72, and (d),(h),(1) $96 \mathrm{~h}$.

From the balanced dynamics viewpoint, the intensification of a vortex can be interpreted from the forcing of heat and momentum sources, which triggers secondary circulation that drives inward advection of absolute angular momentum and results in acceleration of primary circulation (Shapiro and Willoughby 1982; Hendricks et al. 2004; Bui et al. 2009; Heng et al. 2017). The specific vortex characteristics in terms of intensity and radius of maximum wind, as well as the magnitude, radial location, and tilt rate of latent heating could affect the efficiency of latent heating in spinning up the TC (Pendergrass and Willoughby 2009). The vortex response to heat forcing is largely a balanced response, which does not break down the gradient wind balance. To investigate the dynamical effects of changes in diabatic heating caused by the cold-core eddy, the Sawyer-Eliassen equation in height coordinates as Ma (2018) is employed for a further diagnosis. A convergent solution can be obtained when the elliptic criterion is satisfied. The calculation is conducted in a domain with $250-\mathrm{m}$ vertical spacing and $1-\mathrm{km}$ horizontal spacing. Since there are some grid points that the elliptic criterion is not met, primarily in the outflow layer of the upper troposphere, a local adjustment similar as Heng et al. (2017) is applied.

A comparison of the three-dimensional winds at $42 \mathrm{~h}$ for three experiments (Figs. 20a-c) shows that the radial wind, vertical motion, and tangential wind are the strongest in UNCP, followed by NOED, while COUP shows the weakest three-dimensional winds. The eyewall updraft in COUP tends to cover a shallower extent and be located at larger radii relative to that in the other two runs, consistent with its suppressed latent heat release (Fig. 19). Using the diabatic heating at $42 \mathrm{~h}$ as the forcing term (Fig. 19), the Sawyer-Eliassen equation is solved separately for UNCP, COUP, and NOED. The equation-diagnosed radial and vertical winds are shown in Figs. 20d-f. Overall the balanced solution reproduces basically the vertical motion and radial winds from lower troposphere to upper troposphere for all runs. In the boundary layer the radial flow is clearly 
(a) Time evolution of $\mathrm{CB}$ numbers

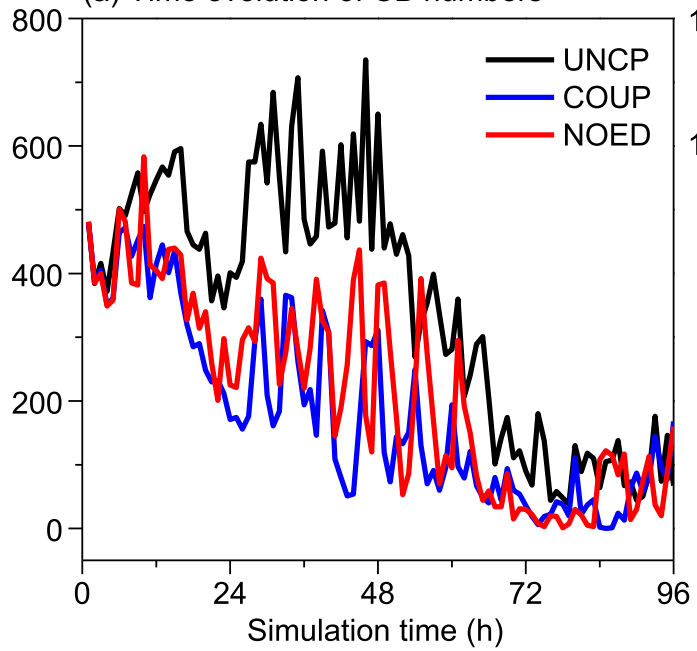

(b) Radial distribution of $\mathrm{CB}$ numbers

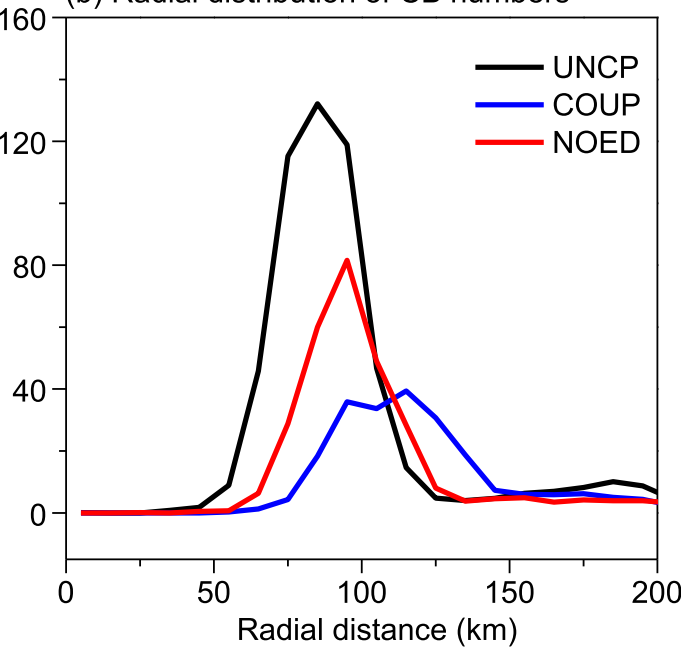

FIG. 18. (a) Time evolution of numbers of convective bursts within a radius of $200 \mathrm{~km}$ from the storm center.

(b) Radial distribution of numbers of convective bursts in each annulus of $10 \mathrm{~km}$ averaged between 24 and $48 \mathrm{~h}$.

underestimated and the low-level outflow jet is absent in the balanced calculation. These two features are primarily caused by the unbalanced contribution of surface friction (Bui et al. 2009). The radial outflow in the upper troposphere is also underestimated, possibly because artificial adjust is made in that region where the elliptic criterion is violated. Consistent with the simulations, the radial inflow, vertical motion, and radial outflow are the weakest in COUP, suggesting that the secondary circulation associated with latent heat release has been inhibited by the cold-core eddy. The weakened secondary circulation by the cold-core eddy leads to smaller tangential wind tendency than the other runs (not shown), and therefore the weakest storm intensity.

\section{Conclusions}

The mechanisms leading to the rapid weakening of Typhoon Francisco (2013) are investigated in this study based on observational analysis and air-sea coupling simulations. The maximum surface wind of Francisco decreased by $45 \mathrm{kt}$ over $24 \mathrm{~h}$ measured from the ADT dataset, being twice larger than that defined as rapid weakening by DeMaria et al. (2012) and close to the largest weakening rate on record. The rapid weakening took place as Francisco crossed over a cold-core eddy at a speed of $3-4 \mathrm{~m} \mathrm{~s}^{-1}$, during which time the atmospheric environment is relatively favorable with weak vertical wind shear and absence of dry-air intrusion.

Francisco was preceded by two typhoons 1-2 weeks before, Danas and Wipha, which have passed over the same eddy. The track of Wipha matched that of Francisco prior to and following eddy passage. Although both typhoons of Danas and Wipha experienced rapid weakening at similar rate to Francisco, their weakening occurred at higher latitude after departure from the eddy. Nonetheless, their passages over the cold-core eddy have amplified the strength of the eddy, with the minimum SSHA increasing from less than 0.08 to $0.24 \mathrm{~m}$. The cold wake generated by Wipha mostly recovered before the arrival of Francisco 6 days later along a similar path, except in the eddy region where the SST remained well below $26^{\circ} \mathrm{C}$. Francisco experienced rapid weakening when crossing over the coldcore eddy and then slightly recovered its intensity after leaving the eddy regime. These observations indicate that the cold-core eddy has played a crucial role in the rapid weakening of Francisco. Although the eddy effect on Danas and Wipha is not remarkable, these two typhoons have increased the strength and size of the cold-core eddy by several times, which may be a prerequisite for the salient role of cold-core eddy in contributing to the weakening of Francisco.

There are also substantial changes in the structures of Francisco accompanying the rapid weakening. A remarkable feature is the evolution from a tiny eye on the order of $20 \mathrm{~km}$ in diameter to a large disorganized eye on the order of $100 \mathrm{~km}$ in diameter. The inner-core surface wind displays overall asymmetric structures with smaller values in the south of the typhoon.

Two atmosphere-ocean coupled experiments with the eddy of interest being removed in one experiment are carried out to isolate the contribution of cold-core 

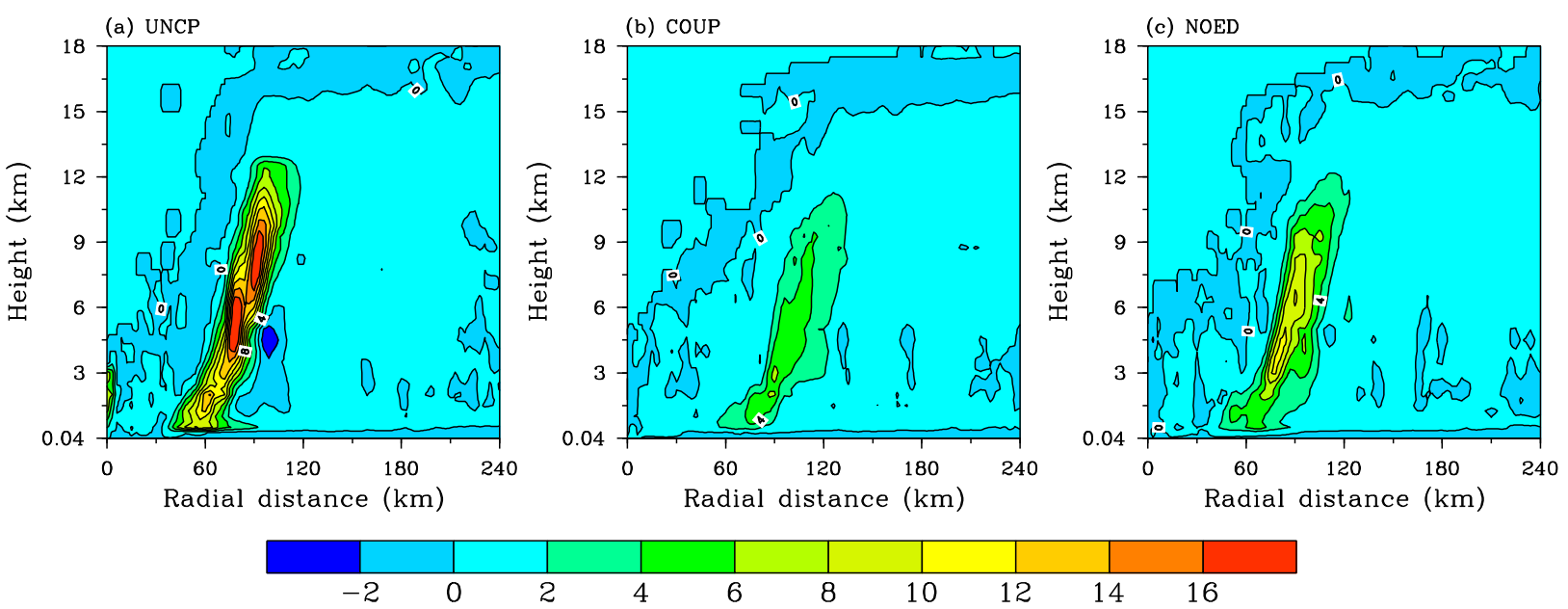

FIG. 19. Height-radius cross sections of azimuthally averaged microphysical diabatic heating rate $\left(10^{-3} \mathrm{~K} \mathrm{~s}^{-1}\right)$ at $42 \mathrm{~h}$ for (a) UNCP, (b) COUP, and (c) NOED.

eddy. A third uncoupled experiment with fixed SST is also conducted to examine the role of cold wake. Both the cold-core eddy and the cold wake are found to be important in the rapid weakening of Francisco. Overall the default coupling experiment reproduces the rapid weakening of Francisco, while the other two runs show stronger storms to different extents. During the storm-eddy interaction, the effect of cold-core eddy on decreasing the intensity is less significant but still comparable to that of cold wake. Besides, the onset of rapid weakening occurs $15 \mathrm{~h}$ later by removing the eddy. This indicates that the cold-core eddy has played a crucial role in contributing to the rapid weakening of Francisco.

The presence of cold-core eddy with dramatically low prestorm $\mathrm{OHC}$ created an unfavorable oceanic condition for the development of Francisco. As the storm encounters the cold-core eddy, cooler subsurface water and stronger upward motion in the eddy regime lead to enhanced cooling in sea surface, which is even cooler than the surface layer. This largely reduces the thermal and moisture disequilibrium at the air-sea surface. As a consequence, the surface latent heat flux is cut down nearly by half due to the eddy contribution. The surface sensible heat flux even turns to be negative above the cold-core eddy. The abrupt drop in surface enthalpy supply results in low values of $\theta_{e}$ in the low-level eye and eyewall region, which have suppressed the convection activities. The $\mathrm{CB}$ numbers are also cut down roughly by half and located at larger radii from the storm center. Consequently, the latent heat release in the eyewall is diminished and located farther from the storm center due to the presence of cold-core eddy. A diagnosis from the Sawyer-Eliassen equation demonstrates that the diminished latent heat release by the cold-core eddy forces much weaker secondary circulation.

The template for the effect of a cold-core eddy on Francisco's rapid weakening can be summarized as follows: A super typhoon with intense surface winds crosses over a cold-core eddy, which has been amplified by two prior typhoons, causing significant decrease of SST together with the cold wake. The sea surface is cooler than the surface layer, leading to an abrupt drop of surface enthalpy supply. The latent heat release associated with convection activities (including CBs) is largely suppressed, and therefore, the secondary circulation becomes undermined. As a consequence, the inward transport of absolute angular momentum is not enough to sustain the storm intensity and thereby the rapid weakening occurs.

There may be several aspects making the cold-core eddy highly significant: 1) two previous typhoons boost the strength of the cold-core eddy and the SST decrease in the eddy region does not fully recover before the arrival of Francisco; 2) the cold-core eddy is located in the subtropical region where the background warm layer is relatively shallow; 3 ) the surface wind of the typhoon is intense to induce a strong ocean response; and 4) the eddy center is directly below the track of Francisco rather than located at the periphery of the storm (Ma et al. 2017). The approximately same spatial scale for eddy and the TC implies that there is possibly a resonant interaction between the eddy and Francisco. Future studies may extend to statistical analysis to examine whether above conclusions drawn from a case investigation are statistically important. The enhanced sea surface cooling by coldcore eddy also causes symmetric and asymmetric changes in thermodynamic and dynamical structures 


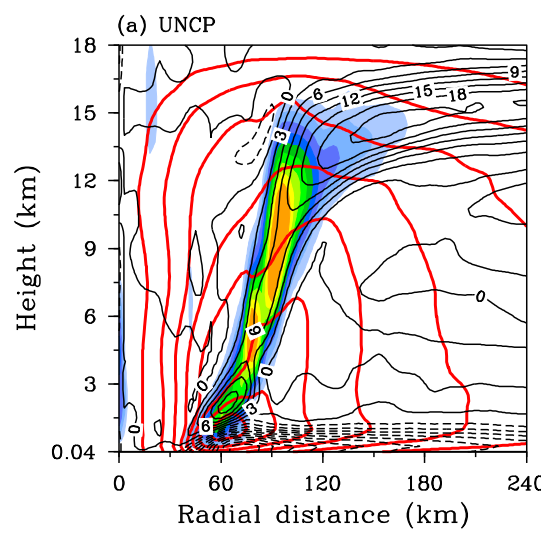

(d) SE for UNCP

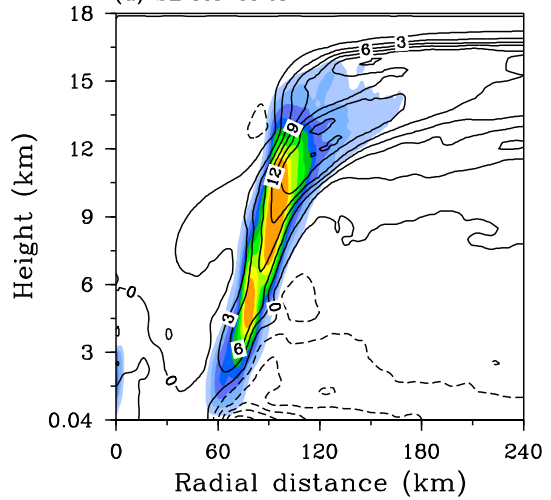

(b) COUP

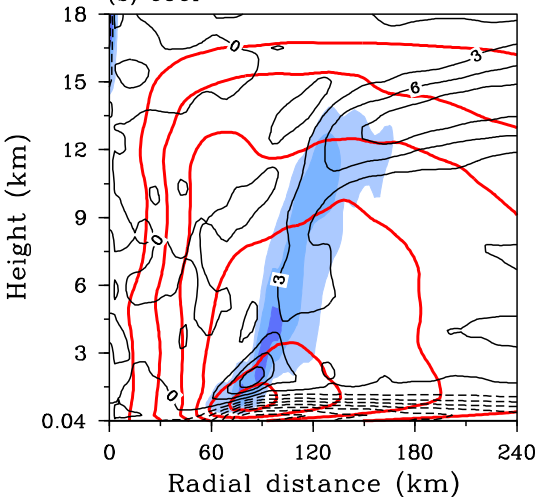

(e) SE for COUP

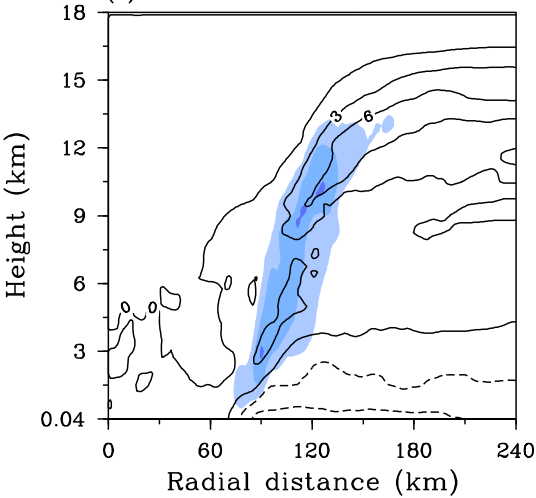

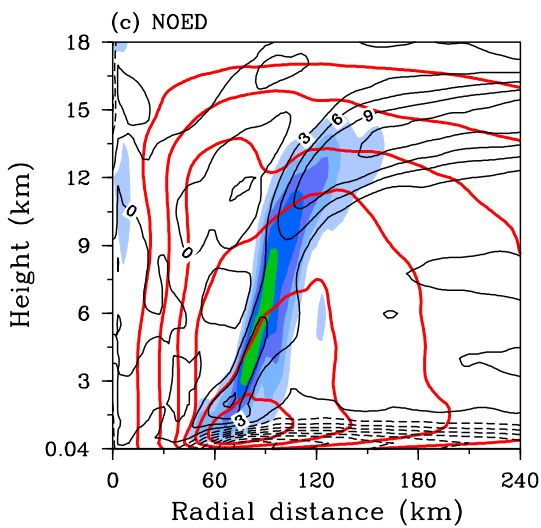

(f) SE for NOED

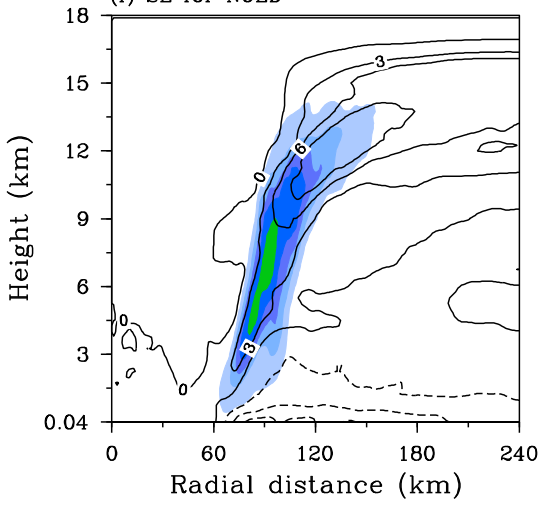

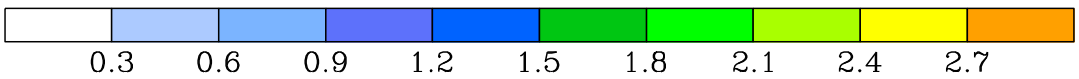

FIG. 20. Height-radius cross sections of azimuthally averaged tangential wind (red contours; $\mathrm{m} \mathrm{s}^{-1}$ ) at an interval of $10 \mathrm{~m} \mathrm{~s}^{-1}$ with the outmost contour being $10 \mathrm{~m} \mathrm{~s}^{-1}$, radial wind (black contours; $\mathrm{m} \mathrm{s}^{-1}$ ), and vertical motion (color shaded; $\mathrm{m} \mathrm{s}^{-1}$ ) at $42 \mathrm{~h} \mathrm{for} \mathrm{(a)} \mathrm{UNCP,}$ (b) COUP, and (c) NOED, and balanced radial wind (black contours; $\mathrm{m} \mathrm{s}^{-1}$ ) and vertical motion (color shaded; $\mathrm{m} \mathrm{s}^{-1}$ ) diagnosed from the Sawyer-Eliassen equation using the heating source in Fig. 19 for (d) UNCP, (e) COUP, and (f) NOED.

of Francisco, which will be presented in a follow-up work (Part II).

Acknowledgments. The author is grateful to Prof. P. Black and two anonymous reviewers for their constructive comments, which helped a lot in improving the manuscript. The author thanks Drs. Lu Yang and Wentao $\mathrm{Wu}$ for their help in configuring the coupled model, and Dr. Huizan Wang for providing the SSHA data information. This work is supported by the National Natural Science Foundation of China with Grant 41875062, 41675058, and 41775053. The SSHA data are available online (from https://www.aviso.altimetry.fr). The SST observation data are obtained from the Remote Sensing Systems dataset (http://www.remss.com). The ADT data are obtained from the Cooperative Institute for Research in the Atmosphere (CIRA) and Cooperative Institute for Meteorological Satellite Studies (CIMSS) website (at http://tropic.ssec.wisc.edu/). The observed horizontal surface wind plots are from Regional and Mesoscale Meteorology Branch (RAMMB; http:// rammb.cira.colostate.edu/). The best track data are from JTWC (http://www.usno.navy.mil/NOOC/nmfc-ph/ RSS/jtwc/best_tracks/wpindex.php), CMA (http:// tcdata.typhoon.org.cn), and JMA (http://www.jma.go.jp/ jma/jma-eng/jma-center/rsmc-hp-pub-eg/trackarchives.html).

\section{REFERENCES}

Black, P., and Coauthors, 2007: Air-sea exchange in hurricanes: Synthesis of observations from the Coupled Boundary Layer Air-Sea Transfer Experiment. Bull. Amer. Meteor. Soc., 88, 357-374, https://doi.org/10.1175/BAMS-88-3-357.

Bui, H. H., R. K. Smith, M. T. Montgomery, and J. Y. Peng, 2009: Balanced and unbalanced aspects of tropical cyclone intensification. Quart. J. Roy. Meteor. Soc., 135, 1715-1731, https:// doi.org/10.1002/qj.502.

Chang, C.-C., and C.-C. Wu, 2017: On the processes leading to the rapid intensification of Typhoon Megi (2010). J. Atmos. Sci., 74, 1169-1200, https://doi.org/10.1175/JAS-D-16-0075.1.

Chelton, D. B., M. G. Schlax, R. M. Samelson, and R. A. de Szoeke, 2007: Global observations of large oceanic eddies. 
Geophys. Res. Lett., 34, L15606, https://doi.org/10.1029/ 2007 GL030812.

Chen, H., and D.-L. Zhang, 2013: On the rapid intensification of Hurricane Wilma (2005). Part II: Convective bursts and the upper-level warm core. J. Atmos. Sci., 70, 146-162, https:// doi.org/10.1175/JAS-D-12-062.1.

— rapid intensification of Hurricane Earl (2010) using the HWRF system. J. Atmos. Sci., 72, 531-550, https://doi.org/ 10.1175/JAS-D-14-0097.1.

Cione, J. J., and E. Uhlhorn, 2003: Sea surface temperature variability in hurricanes: Implications with respect to intensity change. Mon. Wea. Rev., 131, 1783-1796, https:// doi.org/10.1175//2562.1.

Colomb, A., T. Kriat, and M. Leroux, 2019: On the rapid weakening of very intense Tropical Cyclone Hellen (2014). Mon. Wea. Rev., 147, 2717-2737, https://doi.org/10.1175/MWR-D-18-0309.1.

Cram, T. A., J. Persing, M. T. Montgomery, and S. A. Braun, 2007: A Lagrangian trajectory view on transport and mixing processes between the eye, eyewall, and environment using a high-resolution simulation of Hurricane Bonnie (1998). J. Atmos. Sci., 64, 1835-1856, https://doi.org/10.1175/JAS3921.1.

Dare, R. A., and J. L. McBride, 2011a: Sea surface temperature response to tropical cyclones. Mon. Wea. Rev., 139, 3798-3808, https://doi.org/10.1175/MWR-D-10-05019.1.

_ condition for tropical cyclogenesis. J. Climate, 24, 4570-4576, https://doi.org/10.1175/JCLI-D-10-05006.1.

DeMaria, M., R. T. DeMaria, J. A. Knaff, and D. Molenar, 2012: Tropical cyclone lightning and rapid intensity change. Mon. Wea. Rev., 140, 1828-1842, https://doi.org/10.1175/MWR-D11-00236.1.

_ C. C. R. Sampson, J. A. Knaff, and K. D. Musgrave, 2014: Is tropical cyclone intensity guidance improving? Bull. Amer. Meteor. Soc., 95, 387-398, https://doi.org/10.1175/BAMS-D-12-00240.1.

Donelan, M. A., B. K. Haus, N. Reul, W. J. Plant, M. Stiassnie, H. C. Graber, O. B. Brown, and E. S. Saltzman, 2004: On the limiting aerodynamic roughness of the ocean in very strong winds. Geophys. Res. Lett., 31, L18306, https://doi.org/10.1029/ 2004GL019460.

Dudhia, J., 1989: Numerical study of convection observed during the Winter Monsoon Experiment using a mesoscale twodimensional model. J. Atmos. Sci., 46, 3077-3107, https:// doi.org/10.1175/1520-0469(1989)046<3077:NSOCOD>2.0.CO;2.

Elsberry, R., T. D. B. Lambert, and M. A. Boothe, 2007: Accuracy of Atlantic and eastern North Pacific tropical cyclone intensity forecast guidance. Wea. Forecasting, 22, 747-762, https:// doi.org/10.1175/WAF1015.1.

Emanuel, K. A., 1986: An air-sea interaction theory for tropical cyclones. Part I: Steady-state maintenance. J. Atmos. Sci., 43, 585-604, https://doi.org/10.1175/1520-0469(1986)043<0585: AASITF $>2.0 . \mathrm{CO} ; 2$.

— C. DesAutels, C. Holloway, and R. Korty, 2004: Environmental control of tropical cyclone intensity. J. Atmos. Sci., 61, 843-858, https://doi.org/10.1175/1520-0469(2004)061<0843: ECOTCI $>2.0 . \mathrm{CO} ; 2$.

Ge, X., T. Li, and M. Peng, 2013: Effects of vertical shears and midlevel dry air on tropical cyclone developments. J. Atmos. Sci., 70, 3859-3875, https://doi.org/10.1175/JAS-D-13-066.1.

Guimond, S. R., G. M. Heymsfield, and F. J. Turk, 2010: Multiscale observations of Hurricane Dennis (2005): The effects of hot towers on rapid intensification. J. Atmos. Sci., 67, 633-654, https://doi.org/10.1175/2009JAS3119.1.
Halliwell, G. R., S. Gopalakrishnan, F. Marks, and D. Willey, 2015: Idealized study of ocean impacts on tropical cyclone intensity forecasts. Mon. Wea. Rev., 143, 1142-1165, https://doi.org/ 10.1175/MWR-D-14-00022.1.

Harper, B. A., J. D. Kepert, and J. D. Ginger, 2010: Guidelines for converting between various wind averaging periods in tropical cyclone conditions. WMO Tech. Doc. WMO/TD-1555, 54 pp.

Hart, R. E., R. N. Maue, and M. C. Watson, 2007: Estimating local memory of tropical cyclones through MPI anomaly evolution. Mon. Wea. Rev., 135, 3990-4005, https://doi.org/10.1175/ 2007MWR2038.1.

Hendricks, E. A., M. T. Montgomery, and C. A. Davis, 2004: The role of "vortical" hot towers in the formation of Tropical Cyclone Diana (1984). J. Atmos. Sci., 61, 1209-1232, https://doi.org/ 10.1175/1520-0469(2004)061<1209:TROVHT>2.0.CO;2.

_ M. S. Peng, B. Fu, and T. Li, 2010: Quantifying environmental control on tropical cyclone intensity change. Mon. Wea. Rev., 138, 3243-3271, https://doi.org/10.1175/2010MWR3185.1.

Heng, J., Y. Wang, and W. Zhou, 2017: Revisiting the balanced and unbalanced aspects of tropical cyclone intensification. J. Atmos. Sci., 74, 2575-2591, https://doi.org/10.1175/JAS-D-17-0046.1.

Hong, S. Y., Y. Noh, and J. Dudhia, 2006: A new vertical diffusion package with an explicit treatment of entrainment processes. Mon. Wea. Rev., 134, 2318-2341, https://doi.org/10.1175/ MWR3199.1.

Hong, X., S. W. Chang, S. Raman, L. K. Shay, and R. Hodur, 2000: The interaction between Hurricane Opal (1995) and a warm core ring in the Gulf of Mexico. Mon. Wea. Rev., 128, 1347-1365, https:// doi.org/10.1175/1520-0493(2000)128<1347:TIBHOA > 2.0.CO;2.

Houze, R. A., Jr., 2010: Clouds in tropical cyclones. Mon. Wea. Rev., 138, 293-344, https://doi.org/10.1175/2009MWR2989.1.

Jaimes, B., and L. K. Shay, 2009: Mixed layer cooling in mesoscale oceanic eddies during Hurricanes Katrina and Rita. Mon. Wea. Rev., 137, 4188-4207, https://doi.org/10.1175/2009MWR2849.1.

_, and _ 2010: Near-inertial wave wake of Hurricanes Katrina and Rita over mesoscale oceanic eddies. J. Phys. Oceanogr., 40, 1320-1337, https://doi.org/10.1175/2010JPO4309.1.

_, and - 2015: Enhanced wind-driven downwelling flow in warm oceanic eddy features during the intensification of Tropical Cyclone Isaac (2012): Observations and theory. J. Phys. Oceanogr., 45, 1667-1689, https://doi.org/10.1175/JPO-D-14-0176.1.

- — - and E. W. Uhlhorn, 2015: Enthalpy and momentum fluxes during Hurricane Earl relative to underlying ocean features. Mon. Wea. Rev., 143, 111-131, https://doi.org/ 10.1175/MWR-D-13-00277.1.

Jordi, A., and D.-P. Wang, 2012: SbPOM: A parallel implementation of Princeton ocean model. Environ. Modell. Software, 38, 59-61, https://doi.org/10.1016/j.envsoft.2012.05.013.

Kain, J. S., 2004: The Kain-Fritsch convective parameterization: An update. J. Appl. Meteor., 43, 170-181, https://doi.org/ 10.1175/1520-0450(2004)043<0170:TKCPAU > 2.0.CO;2.

Kaplan, J., and M. DeMaria, 2003: Large-scale characteristics of rapidly intensifying tropical cyclones in the North Atlantic basin. Wea. Forecasting, 18, 1093-1108, https://doi.org/ 10.1175/1520-0434(2003)018<1093:LCORIT >2.0.CO;2.

,$- \ldots$, and J. A. Knaff, 2010: A revised tropical cyclone rapid intensification index for the Atlantic and eastern North Pacific basins. Wea. Forecasting, 25, 220-241, https://doi.org/10.1175/ 2009WAF2222280.1.

- and Coauthors, 2015: Evaluating environmental impacts on tropical cyclone rapid intensification predictability utilizing statistical models. Wea. Forecasting, 30, 1374-1396, https:// doi.org/10.1175/WAF-D-15-0032.1. 
Knaff, J. A., C. R. Sampson, and K. D. Musgrave, 2018: An operational rapid intensification prediction aid for the western North Pacific. Wea. Forecasting, 33, 799-811, https://doi.org/ 10.1175/WAF-D-18-0012.1.

Knapp, K. R., and M. C. Kruk, 2010: Quantifying interagency differences in tropical cyclone best-track wind speed estimates. Mon. Wea. Rev., 138, 1459-1473, https://doi.org/ 10.1175/2009MWR3123.1.

_ , J. A. Knaff, C. R. Sampson, G. M. Riggio, and A. D. Schnapp, 2013: A pressure-based analysis of the historical western North Pacific tropical cyclone intensity record. Mon. Wea. Rev., 141, 2611-2631, https://doi.org/10.1175/MWR-D-12-00323.1.

Larson, J., R. Jacob, and E. Ong, 2005: The model coupling toolkit: A new Fortran90 toolkit for building multiphysics parallel coupled models. Int. J. High Perform. Comput. Appl., 19, 277292, https://doi.org/10.1177/1094342005056115.

Leipper, D., and D. Volgenau, 1972: Hurricane heat potential of the Gulf of Mexico. J. Phys. Oceanogr., 2, 218-224, https://doi.org/ 10.1175/1520-0485(1972)002<0218:HHPOTG > 2.0.CO;2.

Liang, J., L. Wu, G. Gu, and Q. Liu, 2016: Rapid weakening of Typhoon Chan-Hom (2015) in a monsoon gyre. J. Geophys. Res. Atmos., 121, 9508-9520, https://doi.org/10.1002/2016JD025214.

$\ldots, \ldots$, and — -2018 : Rapid weakening of tropical cyclones in monsoon gyres over the tropical western North Pacific. J. Climate, 31, 1015-1028, https://doi.org/10.1175/JCLI-D-16-0784.1.

Lin, I.-I., C.-C. Wu, K. A. Emanuel, I.-H. Lee, C.-R. Wu, and I.-F. Pum, 2005: The interaction of Supertyphoon Maemi with a warm ocean eddy. Mon. Wea. Rev., 133, 2635-2649, https:// doi.org/10.1175/MWR3005.1.

, R. D. Farley, and I.-F. Pun, 2008: Upper-ocean thermal structure and the western North Pacific category 5 typhoons. Part I: Ocean features and the category 5 typhoons' intensification. Mon. Wea. Rev., 136, 3288-3306, https://doi.org/ 10.1175/2008MWR2277.1.

- M.-D. Chou, and C.-C. Wu, 2011: The impact of a warm ocean eddy on Typhoon Morakot (2009): A preliminary study from satellite observations and numerical modeling. Terr. Atmos. Ocean. Sci., 22, 661-671, https://doi.org/10.3319/ TAO.2011.08.19.01(TM).

Lin, Y. L., R. D. Farley, and H. D. Orville, 1983: Bulk parameterization of the snow field in a cloud model. J. Appl. Meteor. Climatol., 22, 1065-1092, https://doi.org/10.1175/1520-0450(1983) 022<1065:BPOTSF $>2.0 . \mathrm{CO} ; 2$.

Lloyd, I. D., and G. A. Vecchi, 2011: Observational evidence for oceanic controls on hurricane intensity. J. Climate, 24, 11381153, https://doi.org/10.1175/2010JCLI3763.1.

Ma, Z., 2018: Examining the contribution of surface sensible heat flux induced sensible heating to tropical cyclone intensification from the balance dynamics theory. Dyn. Atmos. Oceans, 84, 33-45, https://doi.org/10.1016/j.dynatmoce.2018.09.001.

_- J. Fei, L. Liu, X. Huang, and X. Cheng, 2013: Effects of the cold core eddy on tropical cyclone intensity and structure under idealized air-sea interaction conditions. Mon. Wea. Rev., 141, 1285-1303, https://doi.org/10.1175/MWR-D-1200123.1

,,-- X. Huang, and X. Cheng, 2015: Contributions of surface sensible heat fluxes to tropical cyclone. Part I: Evolution of tropical cyclone intensity and structure. J. Atmos. Sci., 72, 120 140, https://doi.org/10.1175/JAS-D-14-0199.1.

,,-- L. Liu, X. Huang, and Y. Li, 2017: An investigation of the influences of mesoscale ocean eddies on tropical cyclone intensities. Mon. Wea. Rev., 145, 1181-1201, https://doi.org/ 10.1175/MWR-D-16-0253.1.
—_ - _ X. Xuang, and X. Cheng, 2018: Modulating effects of mesoscale oceanic eddies on sea surface temperature response to tropical cyclones over the western North Pacific. J. Geophys. Res. Atmos., 123, 367-379, https://doi.org/10.1002/ 2017JD027806.

Mainelli, M., M. DeMaria, L. Shay, and G. Goni, 2008: Application of oceanic heat content estimation to operational forecasting of recent Atlantic category 5 hurricanes. Wea. Forecasting, 23, 3-16, https://doi.org/10.1175/2007WAF2006111.1.

Malkus, J. S., and H. Riehl, 1960: On the dynamics and energy transformations in steady-state hurricane. Tellus, 12, 1-20, https://doi.org/10.3402/tellusa.v12i1.9351.

McTaggart-Cowan, R., L. F. Bosart, J. R. Gyakum, and E. H. Atallah, 2007: Hurricane Katrina (2005). Part I: Complex life cycle of an intense tropical cyclone. Mon. Wea. Rev., 135, 3905-3926, https://doi.org/10.1175/2007MWR1875.1.

— , E. Davies, J. Fairman Jr., T. J. Galarneau Jr., and D. Schultz, 2015: Revisiting the $26.5^{\circ} \mathrm{C}$ sea surface temperature threshold for tropical cyclone development. Bull. Amer. Meteor. Soc., 96, 1929-1943, https://doi.org/10.1175/BAMS-D-13-00254.1.

Mei, W., and C. Pasquero, 2013: Spatial and temporal characterization of sea surface temperature response to tropical cyclones. J. Climate, 26, 3745-3765, https://doi.org/10.1175/JCLI-D-1200125.1

Metzger, E. J., and Coauthors, 2010: Validation test report for the Global Ocean Forecast System V3.0-1/128 HYCOM/NCODA: Phase II. NRL Memo. Rep. NRL/MR/7320-10-9236, $70 \mathrm{pp}$.

Miyamoto, Y., and D. Nolan, 2018: Structural changes preceding rapid intensification in tropical cyclones as shown in a large ensemble of idealized simulations. J. Atmos. Sci., 75, 555-569, https://doi.org/10.1175/JAS-D-17-0177.1.

Mlawer, E. J., S. J. Taubman, P. D. Brown, M. J. Iacono, and S. A. Clough, 1997: Radiative transfer for inhomogeneous atmosphere: RRTM, a validated correlated-k model for the longwave. J. Geophys. Res., 102, 16 663-16682, https:// doi.org/10.1029/97JD00237.

Nakazawa, T., and S. Hoshino, 2009: Intercomparison of Dvorak parameters in the tropical cyclone datasets over the western North Pacific. SOLA, 5, 33-36, https://doi.org/10.2151/sola.2009-009.

Pasch, R. J., 2006: Tropical cyclone report: Hurricane Kenneth. National Hurricane Center Rep., 9 pp.

Pendergrass, A. G., and H. E. Willoughby, 2009: Diabatically induced secondary flows in tropical cyclones. Part I: Quasisteady forcing. Mon. Wea. Rev., 137, 805-821, https://doi.org/ 10.1175/2008MWR2657.1.

Persing, J., and M. T. Montgomery, 2003: Hurricane superintensity. J. Atmos. Sci., 60, 2349-2371, https://doi.org/10.1175/15200469(2003)060<2349:HS>2.0.CO;2.

Price, J. F., 1981: Upper ocean response to a hurricane. J. Phys. Oceanogr., 11, 153-175, https://doi.org/10.1175/1520-0485(1981) $011<0153$ :UORTAH $>2.0$. CO; 2 .

_ J. Morzel, and P. P. Niiler, 2008: Warming of SST in the cool wake of a moving hurricane. J. Geophys. Res., 113, C07010, https://doi.org/10.1029/2007JC004393.

Rogers, R., and Coauthors, 2013: NOAA's Hurricane Intensity Forecasting Experiment (IFEX): A progress report. Bull. Amer. Meteor. Soc., 94, 859-882, https://doi.org/10.1175/ BAMS-D-12-00089.1.

Rozoff, C. M., and J. P. Kossin, 2011: New probabilistic forecast models for the prediction of tropical cyclone rapid intensification. Wea. Forecasting, 26, 677-689, https://doi.org/ 10.1175/WAF-D-10-05059.1. 
Shapiro, L. J., and H. E. Willoughby, 1982: The response of balanced hurricanes to local sources of heat and momentum. J. Atmos. Sci., 39, 378-394, https://doi.org/10.1175/15200469(1982)039<0378:TROBHT>2.0.CO;2.

Shay, L. K., 2010: Air-sea interactions in tropical cyclones. Global Perspectives on Tropical Cyclones: From Science to Mitigation, World Scientific, 93-132.

_ - G. J. Goni, and P. G. Black, 2000: Effects of a warm oceanic feature on Hurricane Opal. Mon. Wea. Rev., 128, 1366-1383, https:// doi.org/10.1175/1520-0493(2000)128<1366:EOAWOF>2.0.CO;2.

Skamarock, W. C., and Coauthors, 2008: A description of the Advanced Research WRF version 3. NCAR Tech. Note NCAR/ TN-4751STR, 113 pp., https://doi.org/10.5065/D68S4MVH.

Sun, L., and Coauthors, 2014: Effects of super typhoons on cyclonic ocean eddies in the western North Pacific: A satellite data-based evaluation between 2000 and 2008. J. Geophys. Res. Oceans, 119, 5585-5598, https://doi.org/ 10.1002/2013JC009575.

Tallapragada, V., and C. Kieu, 2014: Real-time forecasts of typhoon rapid intensification in the north western Pacific basin with the NCEP operational HWRF Model. Trop. Cyclone Res. Rev., 3, 63-77, https://doi.org/10.6057/2014TCRR02.01.

Walker, N. D., and Coauthors, 2014: Slow translation speed causes rapid collapse of northeast Pacific Hurricane Kenneth over cold core eddy. Geophys. Res. Lett., 41, 7595-7601, https:// doi.org/10.1002/2014GL061584.

Wang, G., J. Su, and P. Chu, 2003: Mesoscale eddies in the South China Sea observed with altimeter data. Geophys. Res. Lett., 43, 2121, https://doi.org/10.1029/2003GL018532.

Wang, H., and Y. Wang, 2014: A numerical study of Typhoon Megi (2010). Part I: Rapid intensification. Mon. Wea. Rev., 142, 29-48, https://doi.org/10.1175/MWR-D-13-00070.1.
Wang, W., and Coauthors, 2016: ARW: Version 3 modeling system user's guide. NCAR Tech. Note, 408 pp., http://www2.mmm.ucar.edu/wrf/users/docs/user_guide_V3.7/ ARWUsersGuideV3.7.pdf.

Wang, Y., Y. Rao, Z.-M. Tan, and D. Schönemann, 2015: A statistical analysis of the effects of vertical wind shear on tropical cyclone intensity change over the western North Pacific. Mon. Wea. Rev., 143, 3434-3453, https://doi.org/10.1175/MWR-D15-0049.1.

Wood, K. M., and E. A. Ritchie, 2015: A definition for rapid weakening of North Atlantic and eastern North Pacific tropical cyclones. Geophys. Res. Lett., 42, 10 091-10 097, https:// doi.org/10.1002/2015GL066697.

Wu, C.-C., C.-Y. Lee, and I.-I. Lin, 2007: The effect of the ocean eddy on tropical cyclone intensity. J. Atmos. Sci., 64, 35623578, https://doi.org/10.1175/JAS4051.1.

- W.-T. Tu, I.-F. Pun, I.-I. Lin, and M. S. Peng, 2016: Tropical cyclone-ocean interaction in Typhoon Megi (2010)_A synergy study based on ITOP observations and atmosphereocean coupled model simulations. J. Geophys. Res. Atmos., 121, 153-167, https://doi.org/10.1002/2015JD024198

Wu, L., B. Wang, and S. A. Braun, 2005: Impact of air-sea interaction on tropical cyclone track and intensity. Mon. Wea. Rev., 133, 3299-3314, https://doi.org/10.1175/MWR3030.1.

Yablonsky, R. M., and I. Ginis, 2009: Limitation of one-dimensional ocean models for coupled hurricane-ocean model forecasts. Mon. Wea. Rev., 137, 4410-4419, https://doi.org/10.1175/ 2009MWR2863.1.

Zhang, X., Q. Xiao, and P. J. Fitzpatrick, 2007: The impact of multisatellite data on the initialization and simulation of Hurricane Lili's (2002) rapid weakening phase. Mon. Wea. Rev., 135, 526-548, https://doi.org/10.1175/MWR3287.1. 